\title{
Calculation of Multiphase Chemical Equilibrium by the Modified RAND Method
}

\author{
Tsanas, Christos; Stenby, Erling Halfdan; Yan, Wei
}

Published in:

Industrial and Engineering Chemistry Research

Link to article, DOI:

10.1021/acs.iecr.7b02714

Publication date:

2017

Document Version

Peer reviewed version

Link back to DTU Orbit

\section{Citation (APA):}

Tsanas, C., Stenby, E. H., \& Yan, W. (2017). Calculation of Multiphase Chemical Equilibrium by the Modified RAND Method. Industrial and Engineering Chemistry Research, 56(41), 11983-11995.

https://doi.org/10.1021/acs.iecr.7b02714

\section{General rights}

Copyright and moral rights for the publications made accessible in the public portal are retained by the authors and/or other copyright owners and it is a condition of accessing publications that users recognise and abide by the legal requirements associated with these rights.

- Users may download and print one copy of any publication from the public portal for the purpose of private study or research.

- You may not further distribute the material or use it for any profit-making activity or commercial gain

- You may freely distribute the URL identifying the publication in the public portal 


\title{
Calculation of Multiphase Chemical
}

\section{Equilibrium by the Modified RAND Method}

\author{
Christos Tsanas, Erling H. Stenby, and Wei Yan* \\ Center for Energy Resources Engineering (CERE), Department of Chemistry, Technical \\ University of Denmark, 2800 Kongens Lyngby, Denmark \\ E-mail: weya@kemi.dtu.dk
}

\begin{abstract}
A robust and efficient algorithm for simultaneous chemical and phase equilibrium calculations is proposed. It combines two individual non-stoichiometric solving procedures: a nested-loop method with successive substitution for the first steps and final convergence with the second order modified RAND method. The modified RAND extends the classical RAND method from single-phase chemical reaction equilibrium of ideal systems to multiphase chemical equilibrium of non-ideal systems. All components in all phases are treated in the same manner and the system Gibbs energy can be used to monitor convergence. This is the first time that the modified RAND was applied to multiphase chemical equilibrium systems. The combined algorithm was tested using nine examples covering vapor-liquid (VLE) and vapor-liquid-liquid equilibrium (VLLE) of ideal and non-ideal reaction systems. Successive substitution provided good initial estimates for the accelerated computation with the modified RAND, to ultimately converge to the equilibrium solution without failure.
\end{abstract}




\section{Introduction}

A crucial issue in the chemical industry is quick and robust calculations for coupled chemical and phase equilibrium (CPE). The most common application of CPE calculations is in the processes of reactive distillation. Reactions in a distillation column can facilitate separation of isomers or elimination of azeotropes. Additionally, separation can aid reaction equilibrium, leading to higher yields of desirable products. Furthermore, CPE calculations are essential in heterogeneous fuel/chemical synthesis, where products can separate into multiple phases.

Smith and Missen ${ }^{1}$ presented an extensive review of chemical reaction equilibrium methods. Other important studies on chemical equilibrium calculation algorithms were reviewed in our recent paper ${ }^{2}$ and are not repeated in detail here. Smith and Missen ${ }^{1}$ divided CPE calculation algorithms into simultaneous solution of equilibrium equations and Gibbs energy minimization. Methods that minimize the Gibbs energy with respect to extents of reactions and without additional constraints are the stoichiometric methods (unconstrained minimization). On the other hand, those that minimize the Gibbs energy under material balance constraints are the non-stoichiometric methods (constrained minimization). In all minimization methods, a non-negativity constraint for mole numbers exists as well. Nevertheless, it is usually satisfied internally by the procedures without appearing in the formal mathematical treatment.

Stoichiometric methods can be easily extended to multiple phases using a nested loop approach. With a reliable isothermal multiphase flash routine in the inner loop and an outer loop updating the extents of reaction, the minimum of the Gibbs energy can be located in principle. However, the nested loop procedure is not efficient, and there are also numerical concerns about the selection of independent chemical reactions. A proper selection allows

more accurately computed compositions of trace components. ${ }^{3}$ Castier et al. ${ }^{4}$ proposed a second-order stoichiometric method for solving the multiphase chemical reaction problems in non-ideal solution systems. It directly minimizes the system Gibbs energy using extents of reactions and yield factors as independent variables. This is feasible, but the users need to 
take extreme care of the selection of independent variables for the multiple phase equilibrium and the independent chemical reactions at the same time. It should be mentioned that this approach, to the best of our knowledge, is the only second-order convergent method besides the modified RAND to be discussed in this study.

Non-stoichiometric methods are rooted in the approach of Lagrange multipliers. We discussed the application of the Lagrange multipliers to ideal and non-ideal systems using several examples in Tsanas et al. ${ }^{2}$. We presented a linearly convergent algorithm for nonideal systems, which can converge quadratically for ideal systems. Another well-known nonstoichiometric method is the RAND approach, which was originally proposed for single-phase reactions in ideal systems. ${ }^{5}$ RAND is named after the corporation where White et al. ${ }^{5}$ worked at. Smith and Missen ${ }^{1}$ mentioned the RAND with two similar non-stoichiometric methods in the Brinkley-NASA-RAND (BNR) algorithm. ${ }^{5-7}$ The RAND can be extended to multiphase ideal systems, ${ }^{1,8-11}$ requiring the solution of $N_{E}+N_{P}$ equations, where $N_{E}$ is the number of elements in the system and $N_{P}$ the number of phases. Smith and Missen ${ }^{1}$ discussed briefly how the approach could be extended to non-ideal systems. For the single-phase case, there are $N_{C}$ (number of components) linearized equilibrium equations and $N_{E}$ elemental balance equations, but no further details were given on how these equations should be solved. For multiple phases, this treatment will in principle result in $N_{C} N_{P}+N_{E}$ equations. In any case, this number can be quite large, since chemical reaction systems usually involve many components. Recently, Venkatraman et al. ${ }^{12,13}$ used the RAND to calculate equilibrium problems involving reactions in the aqueous phase. They referred to Smith and Missen ${ }^{1}$ for the details of their calculation algorithm.

One possible way to extend the RAND method to non-ideal systems is to perform RAND steps under the ideal vapor/ideal solution assumption (constant fugacity or activity coefficients) and then update the non-ideality part using the new compositions. ${ }^{14}$ This implementation is no longer quadratically convergent. Greiner ${ }^{15}$ presented a non-ideal RAND formulation reducing the number of equations to $N_{E}+N_{P}$ for a multiphase reaction system. 
A variant of Greiner's formulation and its extension to multiple phases was briefly outlined in Michelsen and Mollerup ${ }^{3}$, and more recently, investigated by Paterson et al. ${ }^{16}$. Paterson et al. ${ }^{16}$ presented two formulations: the modified RAND with TP based thermodynamics and the vol-RAND with TV based thermodynamics. However, the study is mainly focused on using the modified RAND to solve multiphase equilibrium calculations without reactions.

In this work we show how the modified RAND can be used to calculate multiphase chemical equilibrium. We present the modified RAND method and implement it on ideal and non-ideal vapor-liquid (VLE), liquid-liquid (LLE) and vapor-liquid-liquid equilibrium (VLLE) of different reaction systems. Computations begin with the assumption of a singlephase. Initialization of the modified RAND is performed by a nested-loop procedure, determining Lagrange multipliers and phase amounts in the inner loop, while updating fugacity or activity coefficients in the outer loop. ${ }^{2}$ This is essentially a first-order successive substitution step. If there is no convergence after three outer-loop iterations, we switch over to the modified RAND, to accelerate calculations. Finally, stability analysis is performed to check whether the current phase set is stable, and if not, to introduce an additional phase. After the introduction of a new phase, the same successive substitution and modified RAND steps are repeated until the obtained solution is proven stable by the stability analysis. The algorithm is efficient and robust, without any incidents of divergence or failure for systems and conditions tested.

\section{Method}

\section{Gibbs energy minimization}

Chemical and phase equilibrium at constant temperature and pressure is determined by minimizing the total Gibbs energy of the system. When $N_{C}$ components undergo $N_{R}$ chemical reactions, they are not independent. Instead, there are $N_{E}=N_{C}-N_{R}$ independent entities required to fully characterize the system and they are called elements. For $N_{P}$ phases, the 
constrained minimization problem under the material balance and non-negativity constraints is formulated as:

$$
\begin{array}{ll} 
& \min _{\mathbf{n}} G(T, p, \mathbf{n})=\min _{n_{i k}} \sum_{k=1}^{N_{P}} \sum_{i=1}^{N_{C}} n_{i k} \mu_{i k}\left(T, p, \mathbf{n}_{k}\right) \\
\text { s.t. } & \sum_{k=1}^{N_{P}} \sum_{i=1}^{N_{C}} A_{j i} n_{i k}=b_{j}, \quad j=1, \ldots, N_{E} \\
& n_{i k} \geq 0, \quad i=1, \ldots, N_{C} \quad k=1, \ldots, N_{P}
\end{array}
$$

where $G$ is the Gibbs energy of the system, $T$ the temperature, $p$ the pressure, $n_{i k}$ and $\mu_{i k}$ the mole numbers and chemical potential of component $i$ in phase $k, \mathbf{n}$ and $\mathbf{n}_{k}$ the component abundance matrix (entries $n_{i k}$ ) and component abundance vector in phase $k, A_{j i}$ the number of elements $j$ in component $i$ and $b_{j}$ the total mole numbers of element $j$.

The material balance in matrix-vector form is expressed in terms of the formula matrix $\mathbf{A}$ and the element abundance vector $\mathbf{b}$ :

$$
\mathbf{A} \sum_{k=1}^{N_{P}} \mathbf{n}_{k}=\mathbf{b}
$$

The element abundance vector is constant no matter how much the reactions progress. Therefore, it is calculable from feed information:

$$
\mathbf{b}=\mathbf{A} \mathbf{n}_{F}
$$

where $\mathbf{n}_{F}$ is the components abundance vector of the single-phase feed. The material balance refers to the total mole numbers of the elements in the system. Mole numbers of elements in phase $k$ are found from $\mathbf{B}_{k}$ :

$$
\mathbf{B}_{k}=\mathbf{A} \mathbf{n}_{k}
$$

and different phases can be combined in the elements abundance matrix $\mathbf{B}$ : 


$$
\mathrm{B}=\mathrm{An}
$$

Linearizing Eq. 2 around the mole numbers estimates, we obtain:

$$
\mathbf{A} \sum_{k=1}^{N_{P}}\left(\mathbf{n}_{k}+\Delta \mathbf{n}_{k}\right)=\mathbf{b}
$$

or

$$
\mathbf{A} \sum_{k=1}^{N_{P}} \Delta \mathbf{n}_{k}=\mathbf{0}
$$

This equation is valid only when mole numbers satisfy the material balance. Otherwise, we have in general:

$$
\mathbf{A} \sum_{k=1}^{N_{P}} \Delta \mathbf{n}_{k}=\Delta \mathbf{b}= \begin{cases}\mathbf{0} & \text { material balance satisfied } \\ \mathbf{b}-\sum_{k=1}^{N_{P}} \mathbf{B}_{k} & \text { material balance not satisfied }\end{cases}
$$

Chemical potentials are calculated by:

$$
\mu_{i k}=\mu_{i k}^{\circ}+R T \ln \frac{\hat{f}_{i k}}{f_{i k}^{\circ}}
$$

where $\mu_{i k}^{\circ}$ and $f_{i k}^{\circ}$ are the reference state chemical potential and reference state fugacity of component $i$ in phase $k, \hat{f}_{i k}$ the fugacity of component $i$ in phase $k$, and $R$ the gas constant. The reference states used in this work are two:

- ideal gas reference state

$$
\mu_{i k}^{\circ}=\mu_{i}^{*}(T) \quad f_{i k}^{\circ}=p^{*} \quad \hat{f}_{i k}=x_{i k} \hat{\phi}_{i k} p
$$

where $\mu_{i}^{*}(T)$ is the ideal gas chemical potential of component $i, p^{*}$ the unit pressure (1 bar or $1 \mathrm{~atm}), x_{i k}$ the mole fraction of component $i$ in phase $k$ and $\hat{\phi}_{i k}$ the fugacity 
coefficient of component $i$ in phase $k$. We choose this reference state when the phase behavior of vapor and liquid phases is modeled by an equation of state.

- pure component reference state

$$
\mu_{i k}^{\circ}=\mu_{i k}^{\mathrm{pure}}(T, p) \quad f_{i k}^{\circ}=f_{i k}(T, p) \quad \hat{f}_{i k}=x_{i k} \gamma_{i k} f_{i k}
$$

where $\mu_{i k}^{\text {pure }}$ and $f_{i k}$ are the chemical potential and fugacity of the pure component $i$ in phase $k$, and $\gamma_{i k}$ the activity coefficient of component $i$ in phase $k$. We choose this reference state for liquid phases that are described by an activity coefficient model. An equivalent fugacity coefficient can be calculated from the activity coefficient:

$$
\hat{\phi}_{i k}=\frac{\gamma_{i k} f_{i k}}{p}
$$

To summarize, depending on the selected reference state, the chemical potential expressions are:

$$
\mu_{i k}= \begin{cases}\mu_{i}^{*}+R T \ln \frac{x_{i k} \hat{\phi}_{i k} p}{p^{*}} & \text { ideal gas ref. state } \\ \mu_{i k}^{\text {pure }}+R T \ln \left(x_{i k} \gamma_{i k}\right) & \text { pure component ref. state }\end{cases}
$$

Since temperature is constant, the reduced Gibbs energy $G /(R T)$ is minimized, as this function will share the same minimizer as the Gibbs energy. The Lagrangian of the reduced Gibbs energy is:

$$
\mathcal{L}(\mathbf{n}, \boldsymbol{\lambda})=\sum_{k=1}^{N_{P}} \sum_{i=1}^{N_{C}} \frac{n_{i k} \mu_{i k}}{R T}-\sum_{j=1}^{N_{E}} \lambda_{j}\left(\sum_{k=1}^{N_{P}} \sum_{i=1}^{N_{C}} A_{j i} n_{i k}-b_{j}\right)
$$

where $\lambda_{j}$ is the Lagrange multiplier of constraint $j$. At the minimum: 


$$
\begin{gathered}
\frac{\partial \mathcal{L}}{\partial n_{i k}}=\frac{\mu_{i k}}{R T}-\sum_{j=1}^{N_{E}} A_{j i} \lambda_{j}=0 \\
i=1, \ldots, N_{C} \quad k=1, \ldots, N_{P}
\end{gathered}
$$

and

$$
\begin{gathered}
\frac{\partial \mathcal{L}}{\partial \lambda_{j}}=-\sum_{k=1}^{N_{P}} \sum_{i=1}^{N_{C}} A_{j i} n_{i k}+b_{j}=0 \\
j=1, \ldots, N_{E}
\end{gathered}
$$

From Eq. 15, at the minimum:

$$
\begin{aligned}
\frac{G_{\min }}{R T} & =\sum_{k=1}^{N_{P}} \sum_{i=1}^{N_{C}} \frac{n_{i k} \mu_{i k}}{R T}=\sum_{k=1}^{N_{P}} \sum_{i=1}^{N_{C}} n_{i k} \sum_{j=1}^{N_{E}} A_{j i} \lambda_{j}= \\
& =\sum_{j=1}^{N_{E}} \lambda_{j} \sum_{k=1}^{N_{P}} \sum_{i=1}^{N_{C}} A_{j i} n_{i k}=\sum_{j=1}^{N_{E}} b_{j} \lambda_{j}
\end{aligned}
$$

which means that the Lagrange multipliers are the reduced chemical potentials of the elements at equilibrium.

\section{The successive substitution method}

A modified set of working equations is solved instead of the Lagrangian conditions at the minimum (Eq. 15 and Eq. 16). In the material balance we substitute $n_{i k}=x_{i k} n_{t, k}$ :

$$
\begin{gathered}
\sum_{k=1}^{N_{P}} n_{t, k} \sum_{i=1}^{N_{C}} A_{j i} x_{i k}-b_{j}=0 \\
j=1, \ldots, N_{E}
\end{gathered}
$$

where $n_{t, k}$ is the total mole numbers of phase $k$ (phase amount), and we force the sum of mole fractions in each phase to be equal to 1 : 


$$
\begin{gathered}
\sum_{i=1}^{N_{C}} x_{i k}-1=0 \\
k=1, \ldots, N_{P}
\end{gathered}
$$

From Eq. 15 we can express mole fractions as a function of the Lagrange multipliers. For the ideal gas reference state:

$$
\ln x_{i k}=\sum_{j=1}^{N_{E}} A_{j i} \lambda_{j}-\frac{\mu_{i}^{*}}{R T}-\ln \frac{\hat{\phi}_{i k} p}{p^{*}}
$$

and for the pure component reference state:

$$
\ln x_{i k}=\sum_{j=1}^{N_{E}} A_{j i} \lambda_{j}-\frac{\mu_{i k}^{\text {pure }}}{R T}-\ln \gamma_{i k}
$$

To determine the equilibrium solution, we need to solve Eq. 18 and Eq. 19 for $N_{E}$ Lagrange multipliers and $N_{P}$ phase amounts, using Eq. 20 or Eq. 21. In a nested-loop, fugacity or activity coefficients are assumed composition independent in the inner loop and updated in the outer loop. From Eq. 20 or Eq. 21, composition independence results in:

$$
\begin{gathered}
\frac{\partial x_{i k}}{\partial \lambda_{q}}=A_{q i} x_{i k} \\
q=1, \ldots, N_{E}
\end{gathered}
$$

and

$$
\begin{gathered}
\frac{\partial x_{i k}}{\partial n_{t, q}}=0 \\
q=1, \ldots, N_{P}
\end{gathered}
$$

The system in the inner loop becomes:

$$
\left[\begin{array}{cc}
\mathbf{A} \operatorname{diag}\left(\sum_{k=1}^{N_{P}} \mathbf{n}_{k}\right) \mathbf{A}^{\mathrm{T}} & \mathbf{A x} \\
(\mathbf{A x})^{\mathrm{T}} & \mathbf{0}
\end{array}\right]\left[\begin{array}{c}
\Delta \boldsymbol{\lambda} \\
\Delta \mathbf{n}_{t}
\end{array}\right]=-\left[\begin{array}{c}
\mathbf{A} \sum_{k=1}^{N_{P}} \mathbf{n}_{k}-\mathbf{b} \\
\mathbf{x}^{\mathrm{T}} \mathbf{e}_{N_{C}}-\mathbf{e}_{N_{P}}
\end{array}\right]
$$


where $\mathbf{x}$ is the mole fraction matrix with entries $x_{i k}$ and $\mathbf{e}_{X}$ is a vector of ones with dimensions $X \times 1$.

\section{The modified RAND method}

The RAND method, originally proposed by White et al. ${ }^{5}$, is only for ideal systems: vapor phases with fugacity coefficients or liquid phases with activity coefficients equal to 1 . We present here its extension to the general case where the equilibrium phases are non-ideal. Eq. 15 can be linearized around the mole numbers estimates:

$$
\begin{gathered}
\frac{\mu_{i k}}{R T}+\sum_{q=1}^{N_{C}} \frac{\partial}{\partial n_{q k}}\left(\frac{\mu_{i k}}{R T}\right) \Delta n_{q k}-\sum_{j=1}^{N_{E}} \lambda_{j} A_{j i}=0 \\
i=1, \ldots, N_{C} \quad k=1, \ldots, N_{P}
\end{gathered}
$$

Mole number derivatives of the chemical potentials are calculated by:

$$
\frac{\partial}{\partial n_{q k}}\left(\frac{\mu_{i k}}{R T}\right)=\frac{\delta_{i q}}{n_{i k}}-\frac{1}{n_{t, k}}+\frac{\partial \ln \hat{\phi}_{i k}}{\partial n_{q k}}
$$

where $\delta_{i q}$ is the Kronecker delta. If an activity coefficient model is used for a liquid phase, activity coefficient derivatives are equivalent (Eq. 12):

$$
\begin{gathered}
\frac{\partial \ln \gamma_{i k}}{\partial n_{q k}}=\frac{\partial \ln \hat{\phi}_{i k}}{\partial n_{q k}} \\
\forall q \neq i \quad k=1, \ldots, N_{P}
\end{gathered}
$$

The corrections to the mole numbers $\Delta n_{i k}$ must be isolated. According to the Gibbs-Duhem equation, the matrix of the mole number derivatives of the chemical potentials in a specific phase is singular:

$$
\begin{gathered}
\sum_{i=1}^{N_{C}} n_{i k} \frac{\partial \mu_{i k}}{\partial n_{q k}}=\sum_{i=1}^{N_{C}} n_{i k} \frac{\partial \ln \hat{\phi}_{i k}}{\partial n_{q k}}=0 \\
q=1, \ldots, N_{C} \quad k=1, \ldots, N_{P}
\end{gathered}
$$


and therefore not invertible. We define the following:

$$
M_{i q k}=\frac{\delta_{i q}}{n_{i k}}+\frac{\partial \ln \hat{\phi}_{i k}}{\partial n_{q k}}
$$

and

$$
s_{k}=\frac{\sum_{i=1}^{N_{C}} \Delta n_{i k}}{n_{t, k}}=\frac{\Delta n_{t, k}}{n_{t, k}}=\frac{\Delta n_{t, k}}{\mathbf{e}_{N_{C}}^{\mathrm{T}} \mathbf{n}_{k}}
$$

The matrix-vector form of Eq. 25 for phase $k$ is:

$$
\begin{gathered}
\frac{\boldsymbol{\mu}_{k}}{R T}+\mathbf{M}_{k} \Delta \mathbf{n}_{k}-s_{k} \mathbf{e}_{N_{C}}-\mathbf{A}^{\mathrm{T}} \boldsymbol{\lambda}=0 \\
k=1, \ldots, N_{P}
\end{gathered}
$$

Corrections for the component abundance vectors are given by:

$$
\begin{gathered}
\Delta \mathbf{n}_{k}=\mathbf{M}_{k}^{-1} \mathbf{e}_{N_{C}} s_{k}+\mathbf{M}_{k}^{-1}\left(\mathbf{A}^{\mathrm{T}} \boldsymbol{\lambda}-\frac{\boldsymbol{\mu}_{k}}{R T}\right) \\
k=1, \ldots, N_{P}
\end{gathered}
$$

From Eq. 28 we obtain:

$$
\begin{gathered}
\mathbf{M}_{k} \mathbf{n}_{k}=\mathbf{e}_{N_{C}} \\
k=1, \ldots, N_{P}
\end{gathered}
$$

and by inverting matrix $\mathbf{M}_{k}$ :

$$
\begin{gathered}
\mathbf{n}_{k}=\mathbf{M}_{k}^{-1} \mathbf{e}_{N_{C}} \\
k=1, \ldots, N_{P}
\end{gathered}
$$

Using Eq. 34, the correction vectors become:

$$
\begin{gathered}
\Delta \mathbf{n}_{k}=\mathbf{n}_{k} s_{k}+\mathbf{M}_{k}^{-1}\left(\mathbf{A}^{\mathrm{T}} \boldsymbol{\lambda}-\frac{\boldsymbol{\mu}_{k}}{R T}\right) \\
k=1, \ldots, N_{P}
\end{gathered}
$$


There are two equations the correction vectors $\Delta \mathbf{n}_{k}$ must satisfy:

$$
\mathbf{A} \sum_{k=1}^{N_{P}} \Delta \mathbf{n}_{k}=\Delta \mathbf{b}
$$

and

$$
\begin{gathered}
\mathbf{e}_{N_{C}}^{\mathrm{T}} \Delta \mathbf{n}_{k}=\Delta n_{t, k} \\
k=1, \ldots, N_{P}
\end{gathered}
$$

Substitution of Eq. 35 in Eq. 36 results in:

$$
\mathbf{A} \sum_{k=1}^{N_{P}} \mathbf{n}_{k} s_{k}+\mathbf{A} \sum_{k=1}^{N_{P}} \mathbf{M}_{k}^{-1} \mathbf{A}^{\mathrm{T}} \boldsymbol{\lambda}-\mathbf{A} \sum_{k=1}^{N_{P}} \mathbf{M}_{k}^{-1} \frac{\boldsymbol{\mu}_{k}}{R T}=\Delta \mathbf{b}
$$

or

$$
\left(\mathbf{A} \sum_{k=1}^{N_{P}} \mathbf{M}_{k}^{-1} \mathbf{A}^{\mathrm{T}}\right) \boldsymbol{\lambda}+\mathbf{B s}=\mathbf{A} \sum_{k=1}^{N_{P}} \mathbf{M}_{k}^{-1} \frac{\boldsymbol{\mu}_{k}}{R T}+\Delta \mathbf{b}
$$

Substitution of Eq. 35 in Eq. 37 results in:

$$
\begin{gathered}
\mathbf{e}_{N_{C}}^{\mathrm{T}} \mathbf{n}_{k} s_{k}+\mathbf{e}_{N_{C}}^{\mathrm{T}} \mathbf{M}_{k}^{-1}\left(\mathbf{A}^{\mathrm{T}} \boldsymbol{\lambda}-\frac{\boldsymbol{\mu}_{k}}{R T}\right)=\Delta n_{t, k} \\
k=1, \ldots, N_{P}
\end{gathered}
$$

Matrix $\mathbf{M}_{k}$ is symmetric, because:

$$
\begin{gathered}
\frac{\partial \ln \hat{\phi}_{i k}}{\partial n_{q k}}=\frac{\partial \ln \hat{\phi}_{q k}}{\partial n_{i k}} \\
\forall q \neq i \quad k=1, \ldots, N_{P}
\end{gathered}
$$

therefore, taking the transpose of Eq. 34:

$$
\begin{gathered}
\mathbf{n}_{k}^{\mathrm{T}}=\mathbf{e}_{N_{C}}^{\mathrm{T}} \mathbf{M}_{k}^{-1} \\
k=1, \ldots, N_{P}
\end{gathered}
$$


From Eq. 30 and Eq. 42, we get in Eq. 40:

$$
\begin{gathered}
\mathbf{n}_{k}^{\mathrm{T}}\left(\mathbf{A}^{\mathrm{T}} \boldsymbol{\lambda}-\frac{\boldsymbol{\mu}_{k}}{R T}\right)=0 \\
k=1, \ldots, N_{P}
\end{gathered}
$$

or

$$
\begin{gathered}
\mathbf{B}_{k}^{\mathrm{T}} \boldsymbol{\lambda}=\frac{\mathbf{n}_{k}^{\mathrm{T}} \boldsymbol{\mu}_{k}}{R T} \\
k=1, \ldots, N_{P}
\end{gathered}
$$

Finally, the modified RAND method for non-ideal multiphase systems requires solving the system of Eq. 39 and Eq. 44:

$$
\left[\begin{array}{cc}
\mathbf{A} \sum_{k=1}^{N_{P}} \mathbf{M}_{k}^{-1} \mathbf{A}^{\mathrm{T}} & \mathbf{B} \\
\mathbf{B}^{\mathrm{T}} & \mathbf{0}
\end{array}\right]\left[\begin{array}{l}
\boldsymbol{\lambda} \\
\mathbf{s}
\end{array}\right]=\left[\begin{array}{c}
\mathbf{A} \sum_{k=1}^{N_{P}} \mathbf{M}_{k}^{-1}\left(\boldsymbol{\mu}_{k} / R T\right)+\Delta \mathbf{b} \\
\mathbf{d}
\end{array}\right]
$$

where:

$$
d_{k}=\frac{\mathbf{n}_{k}^{\mathrm{T}} \boldsymbol{\mu}_{k}}{R T}
$$

If the initial mole numbers estimate satisfies the material balance, the mole numbers at every iteration will satisfy it as well. This is an important advantage of the RAND metod, since the value of the Gibbs energy can be constantly monitored for the potential need of corrective action. At every iteration, $\boldsymbol{\lambda}$ and $\mathbf{s}$ are determined, corrections to the mole numbers are calculated by Eq. 35 and the mole numbers are updated as:

$$
\begin{gathered}
\mathbf{n}_{k}^{(q+1)}=\mathbf{n}_{k}^{(q)}+\alpha \Delta \mathbf{n}_{k}^{(q)} \\
k=1, \ldots, N_{P}
\end{gathered}
$$

where $q$ is the current iteration and $\alpha$ controls the step in case of objective function increase or negative mole numbers. In Eq. 45 , the value of $\Delta \mathbf{b}$ can be set to $\mathbf{0}$, if the initial values of mole numbers satisfy the material balance (Eq. 8). However, in our implementation we 
preserve it in the general form $\Delta \mathbf{b}=\mathbf{b}-\sum_{k=1}^{N_{P}} \mathbf{B}_{k}$, in order to mitigate the effect of round-off errors.

\section{Results and discussion}

The successive substitution and the modified RAND method are combined in a single algorithm for CPE calculations. The slower successive substitution in the beginning provides good quality initial estimates for the efficient calculations with the modified RAND. Initialization of the successive substitution is performed by a robust procedure that requires phase amounts initial guesses. These are kept constant and the following function is minimized with respect to $\boldsymbol{\lambda}$ :

$$
Q(\boldsymbol{\lambda})=\sum_{k=1}^{N_{P}} n_{t, k}\left(\sum_{i=1}^{N_{C}} x_{i k}-1\right)-\sum_{j=1}^{N_{E}} \lambda_{j} b_{j}
$$

This is achieved by solving the system:

$$
\nabla^{2} Q \Delta \boldsymbol{\lambda}=-\nabla Q
$$

or

$$
\left[\mathbf{A} \operatorname{diag}\left(\sum_{k=1}^{N_{P}} \mathbf{n}_{k}\right) \mathbf{A}^{\mathrm{T}}\right] \Delta \boldsymbol{\lambda}=-\left(\mathbf{A} \sum_{k=1}^{N_{P}} \mathbf{n}_{k}-\mathbf{b}\right)
$$

Positive definiteness of $\nabla^{2} Q$ guarantees finding the solution in a finite number of iterations. Initial estimates for successive substitution are the phase amount guesses and the Lagrange multipliers at the $Q$ function minimum. In our treatment, we assume a single-phase when we start the calculations and minimize $Q$ function for ideal vapor or liquid phase (ideal gas or ideal solution). In general, this minimization determines the equilibrium values of $\boldsymbol{\lambda}$ that correspond to a hypothetical system of ideal phases that have the equilibrium phase amounts we initially assumed. As a result, when the guess of the phase amounts is exactly equal to 
their actual equilibrium values and the phases are ideal, $Q$ function minimization determines the final solution of Eq. 24.

We allow successive substitution to run for up to three iterations. If there is no convergence, the modified RAND method is ultimately employed until full convergence. Finally, stability analysis is performed as mentioned in Michelsen ${ }^{17}$, to judge if an additional phase should be considered. The equations are solved again for the new phase set, however, $Q$ function minimization is now skipped. This summarizes the combined algorithm. An alternative algorithm uses only the successive substitution method with the same initialization and stability as mentioned above. This is the successive substitution algorithm. The main steps of the two algorithms can be seen in Figure 1. The error for successive substitution at iteration $q$ is calculated by:

$$
\operatorname{error}^{(q)}=\sqrt{\sum_{j=1}^{N_{E}}\left[\lambda_{j}^{(q)}-\lambda_{j}^{(q-1)}\right]^{2}+\sum_{k=1}^{N_{P}}\left[n_{t, k}^{(q)}-n_{t, k}^{(q-1)}\right]^{2}}
$$

and for the modified RAND by:

$$
\operatorname{error}^{(q)}=\sqrt{\sum_{k=1}^{N_{P}} \sum_{i=1}^{N_{C}}\left[n_{i k}^{(q)}-n_{i k}^{(q-1)}\right]^{2}}
$$

Convergence to the solution is assumed when the error is less than $10^{-10}$. Table 1 presents the numbering of components and elements for all the systems examined. Equilibrium results are reported, along with convergence behavior, where the combined algorithm is expected to perform rapid calculations compared with the slower successive substitution.

\begin{tabular}{|c|c|c|c|c|c|c|}
\hline System & & 1 & 2 & 3 & 4 & 5 \\
\hline $\begin{array}{c}\text { Acetic acid/1-butanol } \\
\text { esterification }\end{array}$ & $\begin{array}{l}\text { Component } \\
\text { Element }\end{array}$ & $\begin{array}{c}\text { Acetic acid } \\
\mathrm{C}_{2} \mathrm{H}_{2} \mathrm{O}\end{array}$ & $\begin{array}{c}\text { 1-Butanol } \\
\mathrm{C}_{4} \mathrm{H}_{10} \mathrm{O}\end{array}$ & $\begin{array}{l}\text { Water } \\
\mathrm{H}_{2} \mathrm{O}\end{array}$ & Butyl acetate & \\
\hline $\begin{array}{l}\text { Propene } \\
\text { hydration }\end{array}$ & $\begin{array}{l}\text { Component } \\
\text { Element }\end{array}$ & $\begin{array}{c}\text { Propene } \\
\mathrm{C}_{3} \mathrm{H}_{6}\end{array}$ & $\begin{array}{l}\text { Water } \\
\mathrm{H}_{2} \mathrm{O}\end{array}$ & 2-Propanol & & \\
\hline $\begin{array}{c}\text { TAME synthesis } \\
1 \text { reaction } \\
2 \text { reactions }\end{array}$ & $\begin{array}{l}\text { Component } \\
\text { Element } \\
\text { Element }\end{array}$ & $\begin{array}{c}\text { 2-Methyl-1-butene } \\
\mathrm{C}_{2.5} \mathrm{H}_{5} \\
\mathrm{C}_{5} \mathrm{H}_{10}\end{array}$ & $\begin{array}{c}\text { 2-Methyl-2-butene } \\
\mathrm{C}_{2.5} \mathrm{H}_{5} \\
\mathrm{CH}_{4} \mathrm{O}\end{array}$ & $\begin{array}{c}\text { Methanol } \\
\mathrm{CH}_{4} \mathrm{O} \\
\mathrm{C}_{5} \mathrm{H}_{12}\end{array}$ & $\begin{array}{l}\text { TAME } \\
\mathrm{C}_{5} \mathrm{H}_{12}\end{array}$ & $n$-Pentane \\
\hline
\end{tabular}

Table 1: Component and element numbering for the systems in this work. 


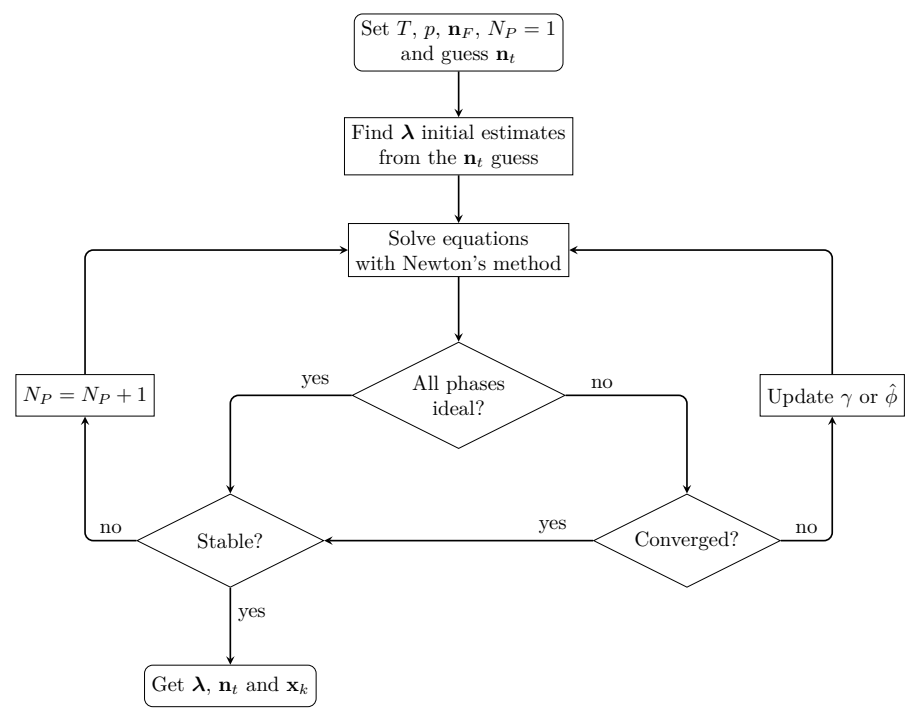

(a)

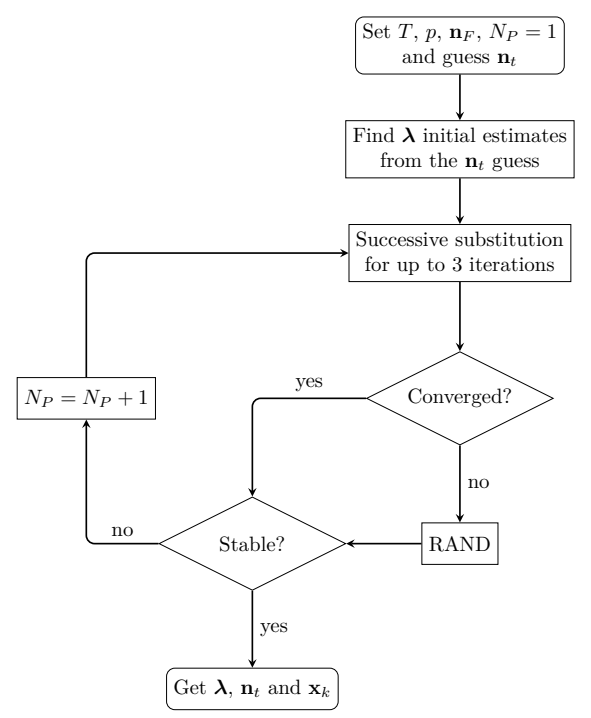

(b)

Figure 1: Main steps for the successive substitution (a) and the combined algorithm (b).

\section{Esterification of acetic acid with 1-butanol}

Wasylkiewicz and Ung ${ }^{18}$ studied the LLE in the esterification of acetic acid with 1-butanol to water and butyl acetate:

$$
\mathrm{C}_{2} \mathrm{H}_{4} \mathrm{O}_{2}+\mathrm{C}_{4} \mathrm{H}_{10} \mathrm{O} \rightleftharpoons \mathrm{H}_{2} \mathrm{O}+\mathrm{C}_{6} \mathrm{H}_{12} \mathrm{O}_{2}
$$

The number of elements is $N_{E}=N_{C}-N_{R}=4-1=3$. The formula matrix and stoichiometric matrix of the system are given by:

$$
\mathbf{A}=\left[\begin{array}{llll}
1 & 0 & 0 & 1 \\
0 & 1 & 0 & 1 \\
1 & 0 & 1 & 0
\end{array}\right] \quad \mathbf{N}=\left[\begin{array}{llll}
-1 & -1 & 1 & 1
\end{array}\right]^{\mathrm{T}}
$$

The vapor phase is considered ideal and liquid phases are described by the UNIQUAC activity coefficient model. ${ }^{19}$ The chemical equilibrium constant was taken from Wasylkiewicz and Ung ${ }^{18}$, vapor pressure expressions and parameters for the UNIQUAC model were taken from Okasinski and Doherty ${ }^{20}$. Calculations for LLE are compared with Bonilla-Petriciolet 
et al. ${ }^{21}$ in Table 2. Transformed compositions of Ung and Doherty ${ }^{22}$ are used:

$$
X_{1 k}=x_{1 k}+x_{4 k} \quad X_{2 k}=x_{2 k}+x_{4 k}
$$

Bonilla-Petriciolet et al. ${ }^{21}$ also define slopes $X_{1 j}^{\prime}$ of the tie lines as:

$$
X_{1 j}^{\prime}=\frac{X_{j 1}-X_{j 2}}{X_{11}-X_{12}}
$$

Moreover, calculations for VLE were made at 1 atm for an equimolar amount of reactants. The phase and mole fractions are presented in Figure 2. Convergence was tested with the successive substitution and the combined algorithm in Figure 3. Legend entry $Q$ represents the $Q$ function minimization, which is the initialization procedure and exhibits quadratic convergence. This uses the same routine for both algorithms and results are therefore identical. The rest of the entries refer to each phase set that we currently attempt to converge to equilibrium. After three iterations of linear convergence with the successive substitution algorithm, the modified RAND converges quadratically to the solution. Especially for the two-phase system, using the combined algorithm results in a marked reduction in the number of iterations.

Table 2: Transformed tie line slopes $X_{12}^{\prime}$ in acetic acid/1-butanol esterification at $298.15 \mathrm{~K}$

\begin{tabular}{|c|c|c|}
\hline Feed vector & Our work & Bonilla-Petriciolet et al. ${ }^{21}$ \\
\hline$\left[\begin{array}{lllll}0.01 & 0.4 & 0.59 & 0\end{array}\right]^{\mathrm{T}}$ & 46.1875 & 46.0948 \\
\hline$\left[\begin{array}{llll}0.1 & 0.2 & 0.7 & 0\end{array}\right]^{\mathrm{T}}$ & 2.6801 & 2.6796 \\
\hline$\left[\begin{array}{llll}0.15 & 0.5 & 0.35 & 0\end{array}\right]^{\mathrm{T}}$ & 3.7591 & 3.7574 \\
\hline$\left[\begin{array}{llll}0.2 & 0.3 & 0.5 & 0\end{array}\right]^{\mathrm{T}}$ & 1.8917 & 1.8920 \\
\hline$\left[\begin{array}{llll}0.3 & 0.3 & 0.4 & 0\end{array}\right]^{\mathrm{T}}$ & 1.3425 & 1.3410 \\
\hline$\left[\begin{array}{llll}0.3 & 0.4 & 0.3 & 0\end{array}\right]^{\mathrm{T}}$ & 1.6227 & 1.6227 \\
\hline$\left[\begin{array}{llll}0.397 & 0.294 & 0.309 & 0\end{array}\right]^{\mathrm{T}}$ & 1.0689 & 1.0649 \\
\hline$\left[\begin{array}{llll}0.394 & 0.274 & 0.332 & 0\end{array}\right]^{\mathrm{T}}$ & 1.0368 & 1.0323 \\
\hline$\left[\begin{array}{llll}0.3 & 0.15 & 0.55 & 0\end{array}\right]^{\mathrm{T}}$ & 0.9759 & 0.9692 \\
\hline$\left[\begin{array}{llll}0.27 & 0.1 & 0.63 & 0\end{array}\right]^{\mathrm{T}}$ & 0.9257 & 0.9176 \\
\hline
\end{tabular}
and 1 atm (1: acetic acid, 2: 1-butanol). 


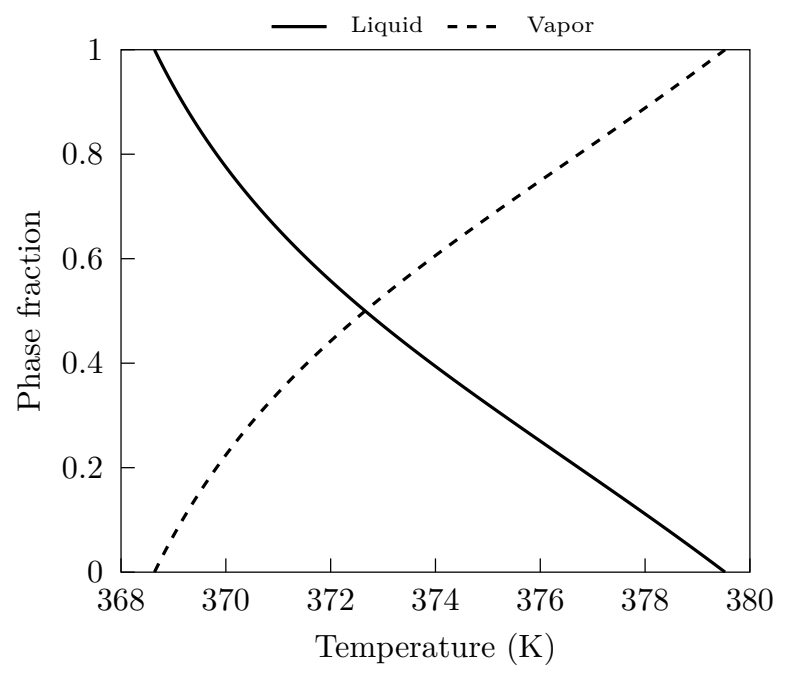

(a)

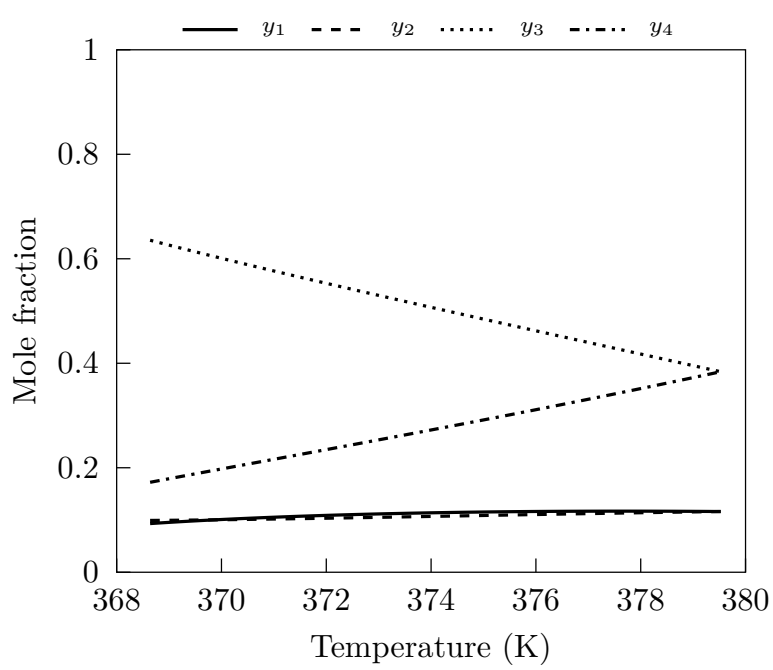

(b)

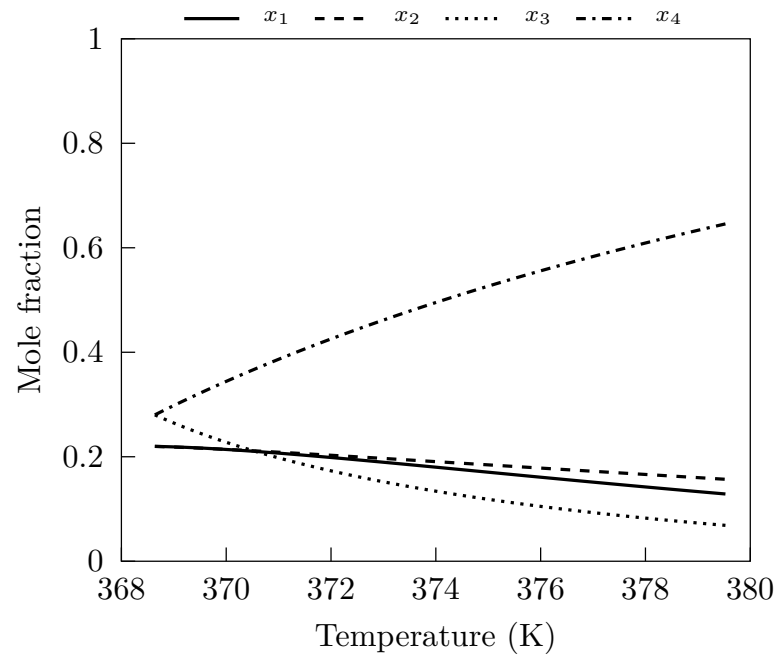

(c)

Figure 2: Phase fractions (a) and mole fractions (b, c) in acetic acid/1-butanol esterification for an equimolar feed of reactants at 1 atm (1: acetic acid, 2: 1-butanol, 3: water, 4: butyl acetate). 


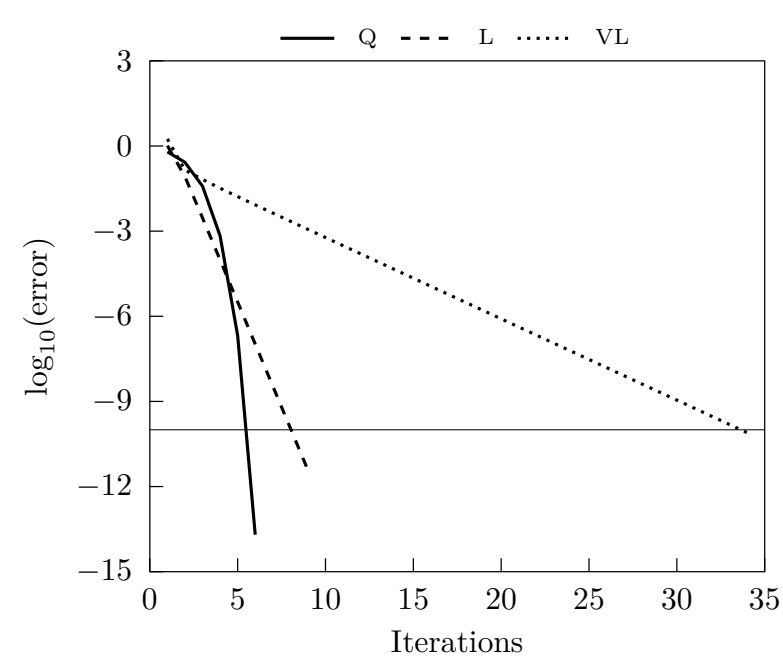

(a)

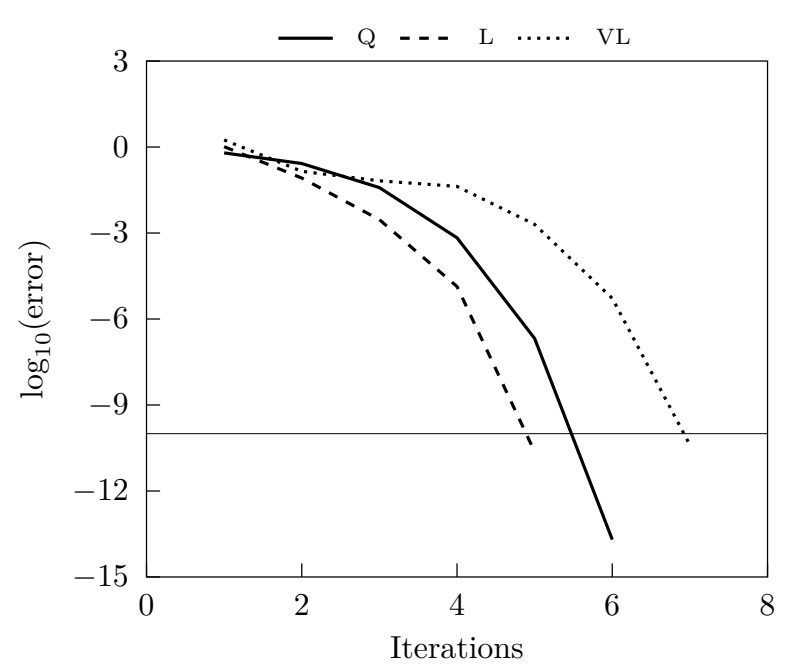

(b)

Figure 3: Convergence in acetic acid/1-butanol esterification for an equimolar feed of reactants at $370 \mathrm{~K}$ and $1 \mathrm{~atm}$ with the successive substitution (a) and the combined algorithm (b).

\section{Propene hydration}

Castier et al. ${ }^{4}$, and Stateva and Wakeham ${ }^{23}$ examined the synthesis of 2-propanol from propene hydration:

$$
\mathrm{C}_{3} \mathrm{H}_{6}+\mathrm{H}_{2} \mathrm{O} \rightleftharpoons \mathrm{C}_{3} \mathrm{H}_{8} \mathrm{O}
$$

The original analysis involved the presence of inert $n$-nonane, giving rise to VLE and VLLE systems for different concentrations of the inert component. In this work, the example of Bonilla-Petriciolet et al. ${ }^{21}$ is tested, where $n$-nonane is absent. The number of elements is $N_{E}=N_{C}-N_{R}=3-1=2$. The formula matrix and stoichiometric matrix of the system are given by:

$$
\mathbf{A}=\left[\begin{array}{lll}
1 & 0 & 1 \\
0 & 1 & 1
\end{array}\right] \quad \mathbf{N}=\left[\begin{array}{lll}
-1 & -1 & 1
\end{array}\right]^{\mathrm{T}}
$$

Vapor and liquid phases are described by the SRK equation of state ${ }^{24}$ without binary in- 
teraction parameters. The chemical equilibrium constant was taken from Bonilla-Petriciolet et al. ${ }^{21}$ and was considered temperature independent. The calculation results using a temperature dependent equilibrium constant are provided in the Supporting Information. Calculations are compared with Bonilla-Petriciolet et al. ${ }^{21}$ for VLE calculations in Table 3. Transformed compositions ${ }^{22}$ are given by:

$$
X_{1 k}=\frac{x_{1 k}+x_{3 k}}{1+x_{3 k}}
$$

For an equimolar amount of reactants, the phase and mole fractions for the VLE of the hydration at 1 bar are presented in Figure 4. Convergence behavior for the two procedures is shown in Figure 5. Although the successive substitution algorithm does not require an excessive number of iterations, the combined algorithm can further reduce their number for both phase sets, L and VL.

Table 3: Transformed compositions $X_{11}$ and $X_{12}$ in propene hydration at $353.15 \mathrm{~K}$ (first subscript - 1: propene, second subscript - 1: vapor, 2: liquid).

\begin{tabular}{cccccc}
\hline Pressure (bar) & \multicolumn{2}{c}{ Our work } & \multicolumn{3}{c}{ Bonilla-Petriciolet et al. $^{21}$} \\
\hline & $X_{11}$ & $X_{12}$ & & $X_{11}$ & $X_{12}$ \\
\cline { 2 - 3 } 1 & 0.3817 & 0.0002 & & 0.3745 & 0.0002 \\
10 & 0.9158 & 0.5673 & & 0.9149 & 0.5663 \\
30 & 0.9802 & 0.8648 & & 0.9800 & 0.8649 \\
\hline
\end{tabular}

\section{TAME synthesis}

Bonilla-Petriciolet et al. ${ }^{21}$ presented VLE calculations for the tert-amyl methyl ether (TAME) synthesis from 2-methyl-1-butene, 2-methyl-2-butene and methanol in the presence of inert $n$-pentane:

$$
2-\mathrm{CH}_{3}-1-\mathrm{C}_{4} \mathrm{H}_{7}+2-\mathrm{CH}_{3}-2-\mathrm{C}_{4} \mathrm{H}_{7}+2 \mathrm{CH}_{4} \mathrm{O} \rightleftharpoons 2 \mathrm{C}_{6} \mathrm{H}_{14} \mathrm{O}
$$

The number of elements is $N_{E}=N_{C}-N_{R}=5-1=4$. The formula matrix and stoichiometric 


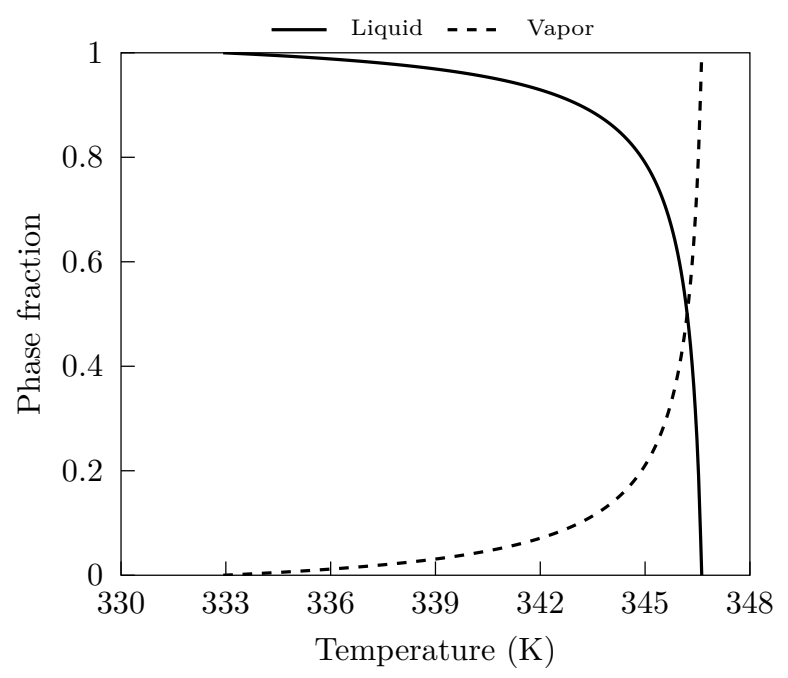

(a)

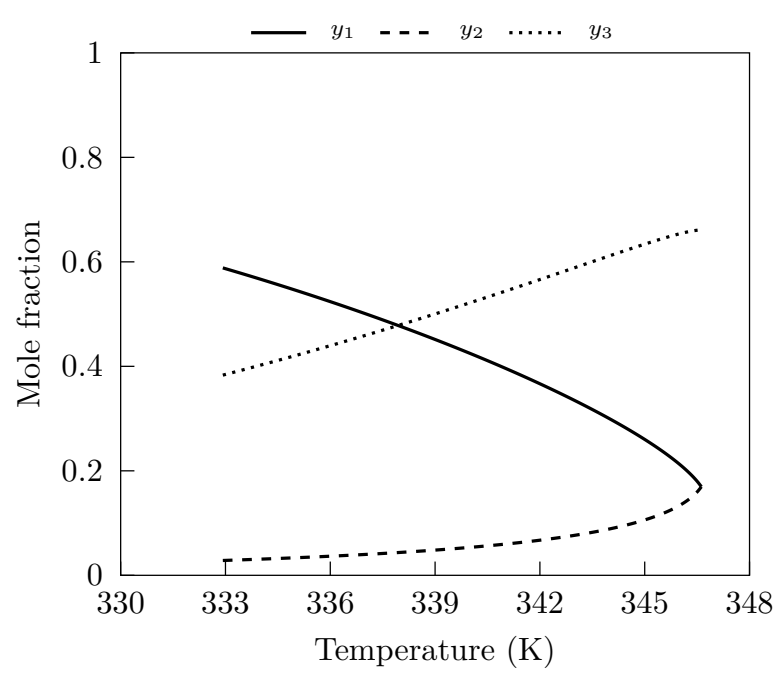

(b)

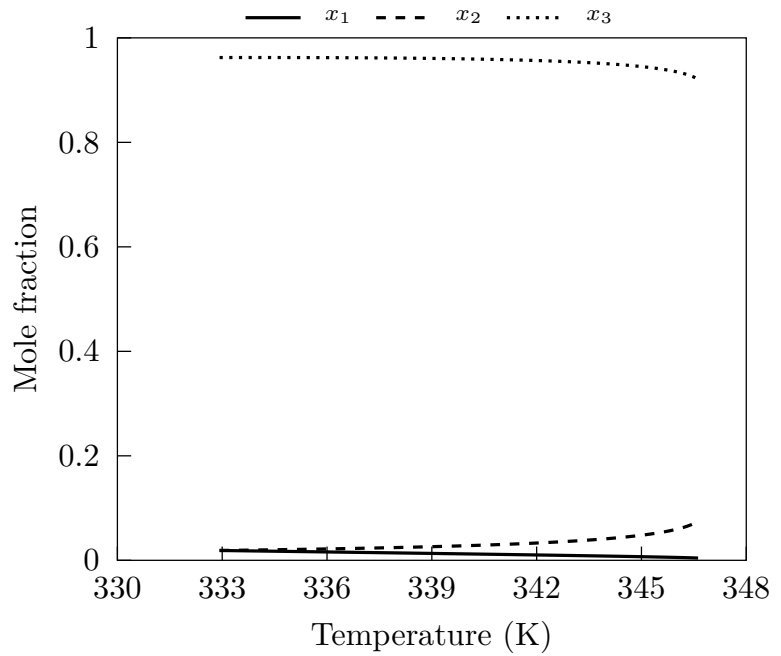

(c)

Figure 4: Phase fractions (a) and mole fractions (b, c) in propene hydration for an equimolar feed of reactants at 1 bar (1: propene, 2: water, 3: 2-propanol). 


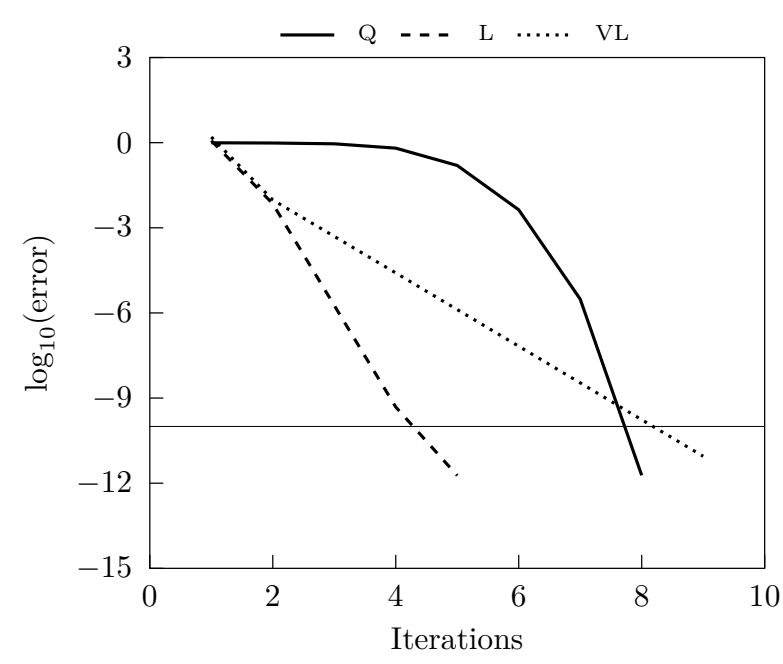

(a)

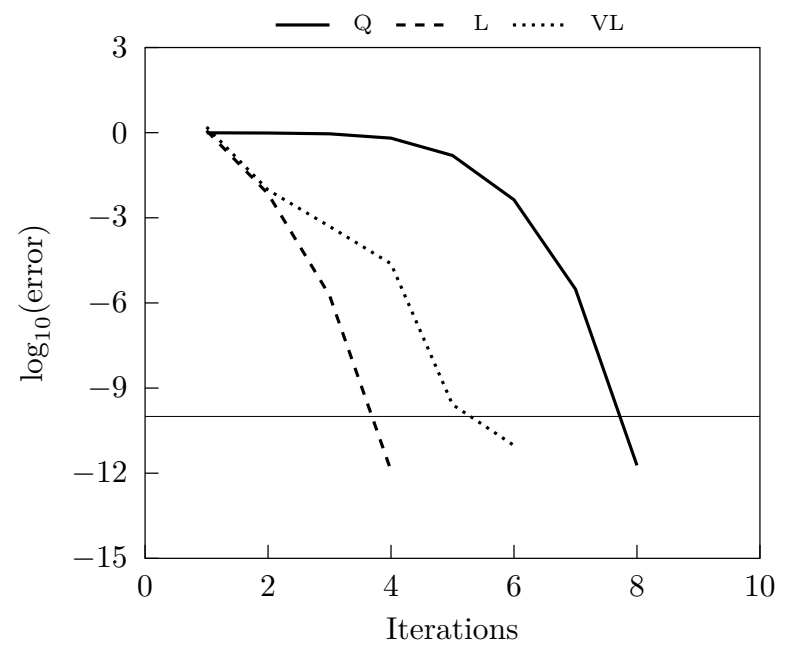

(b)

Figure 5: Convergence in propene hydration for an equimolar feed of reactants at $345 \mathrm{~K}$ and 1 bar with the successive substitution (a) and the combined algorithm (b).

matrix of the system are given by:

$$
\mathbf{A}=\left[\begin{array}{lllll}
2 & 0 & 0 & 1 & 0 \\
0 & 2 & 0 & 1 & 0 \\
0 & 0 & 1 & 1 & 0 \\
0 & 0 & 0 & 0 & 1
\end{array}\right] \quad \mathbf{N}=\left[\begin{array}{lllll}
-1 & -1 & -2 & 2 & 0
\end{array}\right]^{\mathrm{T}}
$$

The vapor phase is considered ideal and the liquid phase is described by the Wilson activity coefficient model. ${ }^{25}$ The chemical equilibrium constant was taken from BonillaPetriciolet et al. ${ }^{21}$, vapor pressure expressions and parameters for the Wilson model were taken from Chen et al. ${ }^{26}$. Calculations are compared with Bonilla-Petriciolet et al. ${ }^{21}$ for the VLE of the system in Table 4. Transformed compositions of Ung and Doherty ${ }^{22}$ are used:

$$
X_{1 k}=\frac{x_{1 k}+0.5 x_{4 k}}{1+x_{4 k}} \quad X_{2 k}=\frac{x_{2 k}+0.5 x_{4 k}}{1+x_{4 k}} \quad X_{3 k}=\frac{x_{3 k}+x_{4 k}}{1+x_{4 k}}
$$

where tie line slopes are defined by Eq. 56.

Chen et al. ${ }^{26}$ study the kinetics in reactive distillation of TAME. In their analysis, two reactions take place in the column: 
Table 4: Transformed tie lines slopes $X_{12}^{\prime}$ and $X_{13}^{\prime}$ in TAME synthesis for the single-reaction system at $335 \mathrm{~K}$ and 1.52 bar (1: 2-methyl-1-butene, 2: 2-methyl-2-butene, 3: methanol).

\begin{tabular}{|c|c|c|c|c|}
\hline \multirow[t]{2}{*}{ Feed vector } & \multicolumn{2}{|c|}{ Our work } & \multicolumn{2}{|c|}{ Bonilla-Petriciolet et al. ${ }^{21}$} \\
\hline & $X_{12}^{\prime}$ & $X_{13}^{\prime}$ & $X_{12}^{\prime}$ & $X_{13}^{\prime}$ \\
\hline$\left[\begin{array}{lllll}0.3 & 0.15 & 0.55 & 0 & 0\end{array}\right]^{\mathrm{T}}$ & -0.2083 & - & -0.2072 & - \\
\hline$\left[\begin{array}{lllll}0.32 & 0.2 & 0.48 & 0 & 0\end{array}\right]^{\mathrm{T}}$ & -0.2813 & - & -0.2800 & - \\
\hline$\left[\begin{array}{lllll}0.354 & 0.183 & 0.463 & 0 & 0\end{array}\right]^{\mathrm{T}}$ & -0.2869 & - & -0.2856 & - \\
\hline$\left[\begin{array}{lllll}0.2 & 0.07 & 0.73 & 0 & 0\end{array}\right]^{\mathrm{T}}$ & -0.0079 & - & -0.0076 & - \\
\hline$\left[\begin{array}{lllll}0.15 & 0.02 & 0.83 & 0 & 0\end{array}\right]^{\mathrm{T}}$ & 0.0063 & - & 0.0064 & - \\
\hline$\left[\begin{array}{lllll}0.27 & 0.3 & 0.43 & 0 & 0\end{array}\right]^{\mathrm{T}}$ & 0.8050 & - & 0.8089 & - \\
\hline$\left[\begin{array}{lllll}0.2 & 0.35 & 0.45 & 0 & 0\end{array}\right]^{\mathrm{T}}$ & -3.6530 & - & -3.6767 & - \\
\hline$\left[\begin{array}{lllll}0.1 & 0.35 & 0.55 & 0 & 0\end{array}\right]^{\mathrm{T}}$ & -8.4680 & - & -8.5301 & - \\
\hline$\left[\begin{array}{lllll}0.05 & 0.3 & 0.65 & 0 & 0\end{array}\right]^{\mathrm{T}}$ & -157.8824 & - & -162.6184 & - \\
\hline$\left[\begin{array}{lllll}0.025 & 0.3 & 0.675 & 0 & 0\end{array}\right]^{\mathrm{T}}$ & 334.3359 & - & 327.5080 & - \\
\hline$\left[\begin{array}{lllll}0.15 & 0.02 & 0.8 & 0 & 0.03\end{array}\right]^{\mathrm{T}}$ & 0.0098 & -1.2428 & 0.0099 & -1.2428 \\
\hline$\left[\begin{array}{lllll}0.1 & 0.1 & 0.6 & 0 & 0.2\end{array}\right]^{\mathrm{T}}$ & 0.9404 & -5.8388 & 0.9406 & -5.8340 \\
\hline$\left[\begin{array}{lllll}0.05 & 0.05 & 0.85 & 0 & 0.05\end{array}\right]^{\mathrm{T}}$ & 0.8065 & -6.2504 & 0.8069 & -6.2438 \\
\hline$\left[\begin{array}{lllll}0.1 & 0.15 & 0.7 & 0 & 0.05\end{array}\right]^{\mathrm{T}}$ & 6.0678 & -13.5463 & 6.0243 & -13.4445 \\
\hline$\left[\begin{array}{lllll}0.15 & 0.15 & 0.6 & 0 & 0.1\end{array}\right]^{\mathrm{T}}$ & 0.8456 & -4.0466 & 0.8465 & -4.0396 \\
\hline$\left[\begin{array}{lllll}0.07 & 0.17 & 0.64 & 0 & 0.12\end{array}\right]^{\mathrm{T}}$ & 7.9465 & -18.0942 & 7.9130 & -18.0152 \\
\hline
\end{tabular}

$$
\begin{aligned}
& 2-\mathrm{CH}_{3}-1-\mathrm{C}_{4} \mathrm{H}_{7}+\mathrm{CH}_{4} \mathrm{O} \rightleftharpoons \mathrm{C}_{6} \mathrm{H}_{14} \mathrm{O} \\
& 2-\mathrm{CH}_{3}-2-\mathrm{C}_{4} \mathrm{H}_{7}+\mathrm{CH}_{4} \mathrm{O} \rightleftharpoons \mathrm{C}_{6} \mathrm{H}_{14} \mathrm{O}
\end{aligned}
$$

creating a different reaction system. The number of elements is now $N_{E}=N_{C}-N_{R}=$ $5-2=3$. The formula matrix and stoichiometric matrix of the system are given by:

$$
\mathbf{A}=\left[\begin{array}{lllll}
1 & 1 & 0 & 1 & 0 \\
0 & 0 & 1 & 1 & 0 \\
0 & 0 & 0 & 0 & 1
\end{array}\right] \quad \mathbf{N}=\left[\begin{array}{ccccc}
-1 & 0 & -1 & 1 & 0 \\
0 & -1 & -1 & 1 & 0
\end{array}\right]^{\mathrm{T}}
$$

The chemical equilibrium constants for the two reactions were taken from Chen et al. ${ }^{26}$. Although Bonilla-Petriciolet et al. ${ }^{21}$ combined the two reactions by addition (Eq. 60 ), the 
chemical equilibrium constant they use corresponds to the reaction of Eq. 63 according to Chen et al. ${ }^{26}$. For a stoichiometric feed of reactants and methanol $/ n$-pentane ratio $2: 1$, the phase and mole fractions for the two-reaction VLE calculations at 1.52 bar are presented in Figure 6. Convergence for the 2-reaction TAME synthesis is shown in Figure 7. It is evident that the successive substitution algorithm requires two to three times more iterations to fully converge, in comparison with the combined algorithm which performs much faster calculations.

\section{Comparison of convergence with previously reported systems}

Several systems were tested in previous work using only the successive substitution algorithm. ${ }^{2}$ Components and elements of the additional systems are presented in Table 5. Convergence behavior will be examined with the combined algorithm and compared with successive substitution results.

Table 5: Component and element numbering for the systems tested in previous work.

\begin{tabular}{|c|c|c|c|c|c|c|c|c|}
\hline System & & 1 & 2 & 3 & 4 & 5 & 6 & 7 \\
\hline $\begin{array}{l}\text { Formaldehyde/ } \\
\text { water }\end{array}$ & $\begin{array}{l}\text { Component } \\
\text { Element }\end{array}$ & $\begin{array}{l}\text { Formaldehyde } \\
\qquad \mathrm{CH}_{2} \mathrm{O}\end{array}$ & $\begin{array}{l}\text { Water } \\
\mathrm{H}_{2} \mathrm{O}\end{array}$ & Methylene glycol & Oxydimethanol & & & \\
\hline $\begin{array}{c}\text { Xylene } \\
\text { separation }\end{array}$ & $\begin{array}{l}\text { Component } \\
\text { Element }\end{array}$ & $\begin{array}{l}\text { Di-tert-butylbenzene } \\
\qquad \mathrm{C}_{6} \mathrm{H}_{6}\end{array}$ & $\begin{array}{c}m \text {-Xylene } \\
\mathrm{C}_{4} \mathrm{H}_{8}\end{array}$ & $\begin{array}{l}\text { tert-Butyl-m-xylene } \\
\mathrm{C}_{8} \mathrm{H}_{10}\end{array}$ & $\begin{array}{l}\text { tert-Butylbenzene } \\
\mathrm{C}_{8} \mathrm{H}_{10}\end{array}$ & Benzene & p-Xylene & \\
\hline $\begin{array}{c}\text { Acetic acid/ethanol } \\
\text { esterification }\end{array}$ & $\begin{array}{l}\text { Component } \\
\text { Element }\end{array}$ & $\begin{array}{c}\text { Acetic acid } \\
\mathrm{C}_{2} \mathrm{H}_{2} \mathrm{O} \\
\end{array}$ & $\begin{array}{l}\text { Ethanol } \\
\mathrm{C}_{2} \mathrm{H}_{6} \mathrm{O}\end{array}$ & $\begin{array}{l}\text { Water } \\
\mathrm{H}_{2} \mathrm{O} \\
\end{array}$ & Ethyl acetate & & & \\
\hline $\begin{array}{c}\text { MTBE } \\
\text { synthesis }\end{array}$ & $\begin{array}{l}\text { Component } \\
\text { Element }\end{array}$ & $\begin{array}{c}\text { Isobutene } \\
\mathrm{C}_{4} \mathrm{H}_{8}\end{array}$ & $\begin{array}{l}\text { Methanol } \\
\mathrm{CH}_{4} \mathrm{O}\end{array}$ & $\begin{array}{c}n \text {-Butane } \\
\mathrm{C}_{4} \mathrm{H}_{10}\end{array}$ & MTBE & & & \\
\hline $\begin{array}{l}\text { Cyclohexane } \\
\text { synthesis }\end{array}$ & $\begin{array}{l}\text { Component } \\
\text { Element }\end{array}$ & $\begin{array}{c}\text { Benzene } \\
\mathrm{C}_{6} \mathrm{H}_{6}\end{array}$ & $\begin{array}{l}\text { Hydrogen } \\
\mathrm{H}_{2}\end{array}$ & Cyclohexane & & & & \\
\hline $\begin{array}{l}\text { Methanol } \\
\text { synthesis }\end{array}$ & $\begin{array}{l}\text { Component } \\
\text { Element }\end{array}$ & $\begin{array}{c}\text { Carbon monoxide } \\
\text { CO }\end{array}$ & $\begin{array}{c}\text { Carbon dioxide } \\
\text { O }\end{array}$ & $\begin{array}{c}\text { Hydrogen } \\
\mathrm{H}_{2}\end{array}$ & $\begin{array}{l}\text { Water } \\
\mathrm{CH}_{4}\end{array}$ & $\begin{array}{c}\text { Methanol } \\
\mathrm{C}_{18} \mathrm{H}_{38}\end{array}$ & Methane & Octadecane \\
\hline
\end{tabular}

\section{Formaldehyde/water based system and xylene separation}

Formaldehyde dimerization is studied based on the following reactions: 


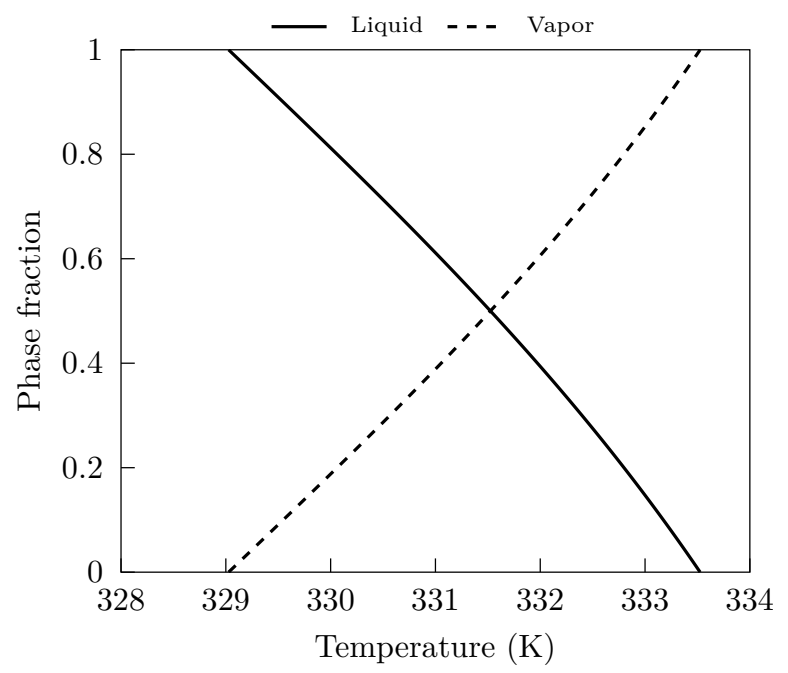

(a)

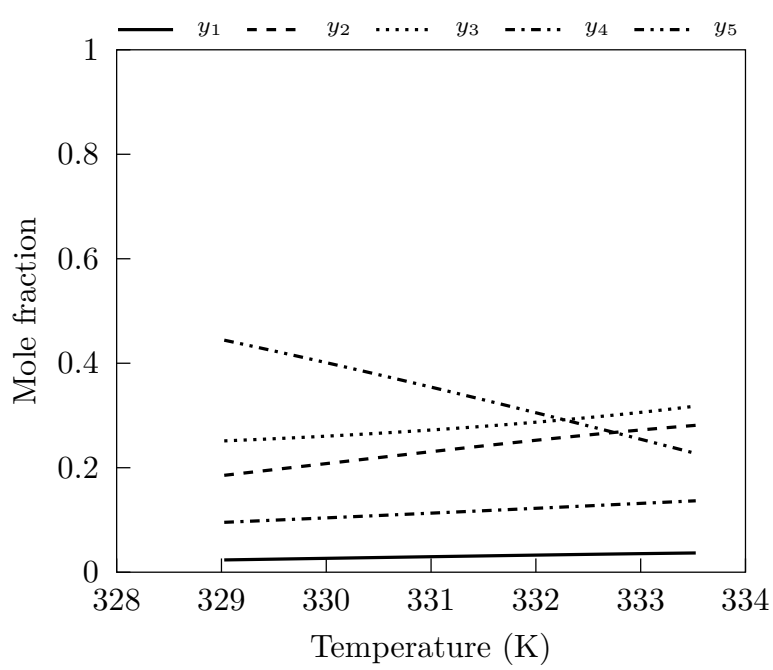

(b)

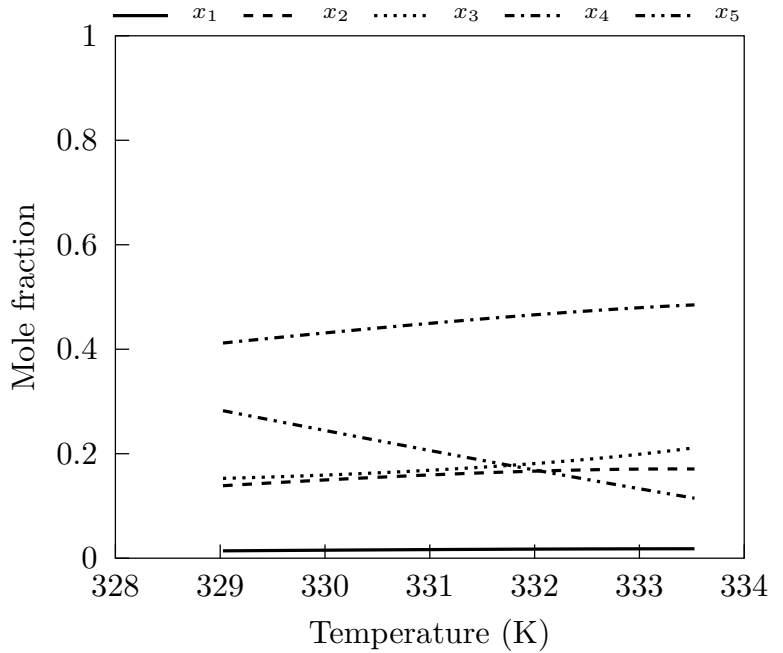

(c)

Figure 6: Phase fractions (a) and vapor/liquid phase mole fractions (b, c) in TAME synthesis at 1.52 bar for a stoichiometric feed of reactants and methanol $/ n$-pentane ratio $2: 1$ (1: 2methyl-1-butene, 2: 2-methyl-2-butene, 3: methanol, 4: TAME, 5: n-pentane). 


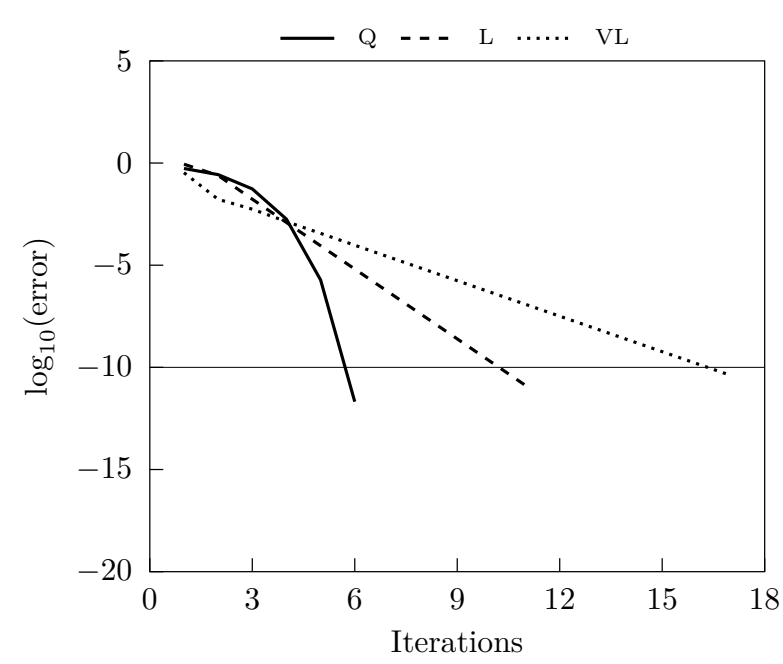

(a)

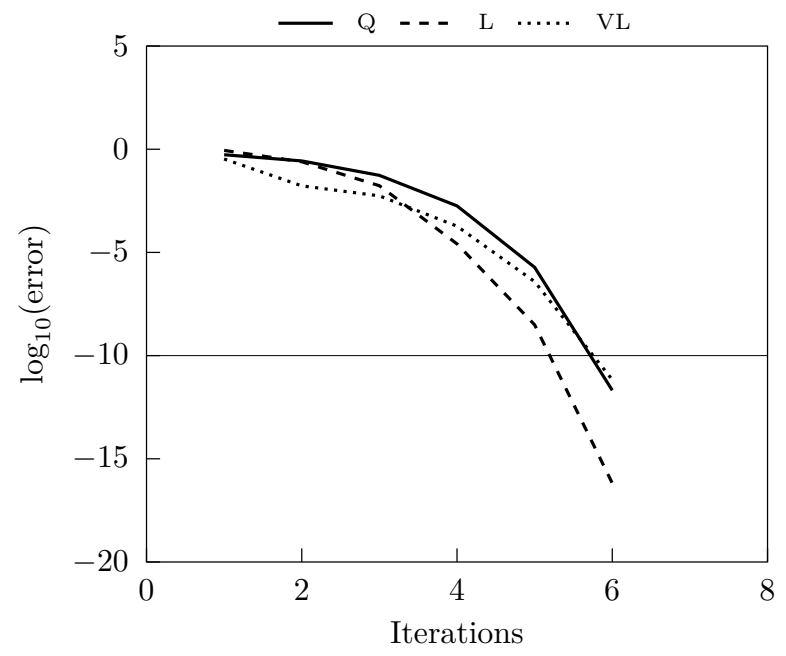

(b)

Figure 7: Convergence in TAME synthesis for a stoichiometric feed of reactants and methanol/n-pentane ratio $2: 1$ at $330 \mathrm{~K}$ and 1.52 bar with the successive substitution (a) and the combined algorithm (b).

$$
\begin{gathered}
\mathrm{CH}_{2} \mathrm{O}+\mathrm{H}_{2} \mathrm{O} \rightleftharpoons \mathrm{CH}_{4} \mathrm{O}_{2} \\
2 \mathrm{CH}_{4} \mathrm{O}_{2} \rightleftharpoons \mathrm{C}_{2} \mathrm{H}_{6} \mathrm{O}_{3}+\mathrm{H}_{2} \mathrm{O}
\end{gathered}
$$

where formaldehyde reacts with water to produce methylene glycol, and two molecules of methylene glycol produce oxydimethanol and water. Chemical equilibrium constants were taken from Maurer ${ }^{27}$. Formula and stoichiometric matrix are:

$$
\mathbf{A}=\left[\begin{array}{llll}
1 & 0 & 1 & 2 \\
0 & 1 & 1 & 1
\end{array}\right] \quad \mathbf{N}=\left[\begin{array}{cccc}
-1 & -1 & 1 & 0 \\
0 & 1 & -2 & 1
\end{array}\right]^{\mathrm{T}}
$$

A mixture of xylenes, $m$-xylene and $p$-xylene, can be separated by reactive distillation, since the former participates in the reactions: 


$$
\begin{aligned}
& \mathrm{C}_{14} \mathrm{H}_{22}+m-\mathrm{C}_{8} \mathrm{H}_{10} \rightleftharpoons \mathrm{C}_{12} \mathrm{H}_{18}+\mathrm{C}_{10} \mathrm{H}_{14} \\
& \mathrm{C}_{10} \mathrm{H}_{14}+m-\mathrm{C}_{8} \mathrm{H}_{10} \rightleftharpoons \mathrm{C}_{12} \mathrm{H}_{18}+\mathrm{C}_{6} \mathrm{H}_{6}
\end{aligned}
$$

where di-tert-butylbenzene reacts with $m$-xylene to give tert-butyl- $m$-xylene and tert-butylbenzene, while tert-butylbenzene reacts with $m$-xylene to produce tert-butyl- $m$-xylene and benzene ( $p$-xylene is an inert). Chemical equilibrium constants were taken from Saito et al. ${ }^{28}$. Formula matrix and stoichiometric matrix are:

$$
\mathbf{A}=\left[\begin{array}{llllll}
1 & 0 & 0 & 1 & 1 & 0 \\
2 & 0 & 1 & 1 & 0 & 0 \\
0 & 1 & 1 & 0 & 0 & 0 \\
0 & 0 & 0 & 0 & 0 & 1
\end{array}\right] \quad \mathbf{N}=\left[\begin{array}{cccccc}
-1 & -1 & 1 & 1 & 0 & 0 \\
0 & -1 & 1 & -1 & 1 & 0
\end{array}\right]^{\mathrm{T}}
$$

The vapor and the liquid phase of both systems were considered ideal. As a result, there is no need for an outer loop to update activity coefficients. This allows the successive substitution algorithm to attain quadratic convergence rate and no direct comparison was made with the combined algorithm.

\section{Esterification of acetic acid with ethanol}

Esterification of acetic acid with ethanol to water and ethyl acetate is given by the reaction:

$$
\mathrm{C}_{2} \mathrm{H}_{4} \mathrm{O}_{2}+\mathrm{C}_{2} \mathrm{H}_{6} \mathrm{O} \rightleftharpoons \mathrm{C}_{4} \mathrm{H}_{8} \mathrm{O}_{2}+\mathrm{H}_{2} \mathrm{O}
$$

The vapor phase is considered ideal and the liquid phase is described by the UNIQUAC activity coefficient model. ${ }^{19}$ The chemical equilibrium constant and parameters for the phase equilibrium model were reported in Xiao et al. ${ }^{29}$. Formula matrix and stoichiometric matrix are: 


$$
\mathbf{A}=\left[\begin{array}{llll}
1 & 0 & 0 & 1 \\
0 & 1 & 0 & 1 \\
1 & 0 & 1 & 0
\end{array}\right] \quad \mathbf{N}=\left[\begin{array}{llll}
-1 & -1 & 1 & 1
\end{array}\right]^{\mathrm{T}}
$$

In Figure 8 convergence of the two reported procedures is presented. When successive substitution is employed (successive substitution algorithm or the first steps of the combined algorithm), only the outer loop iterations are shown. For this system we begin with the assumption of a single ideal vapor phase. Moreover, the total mole numbers do not change due to the reaction, which means that the phase amount is known at the supposed singlephase equilibrium. Therefore, minimization of function $Q$ produces the actual equilibrium concentrations of the single ideal vapor phase and successive substitution is not needed. For the two-phase system, we obtain the solution in 7 iterations with the combined algorithm, compared to 44 with just successive substitution.

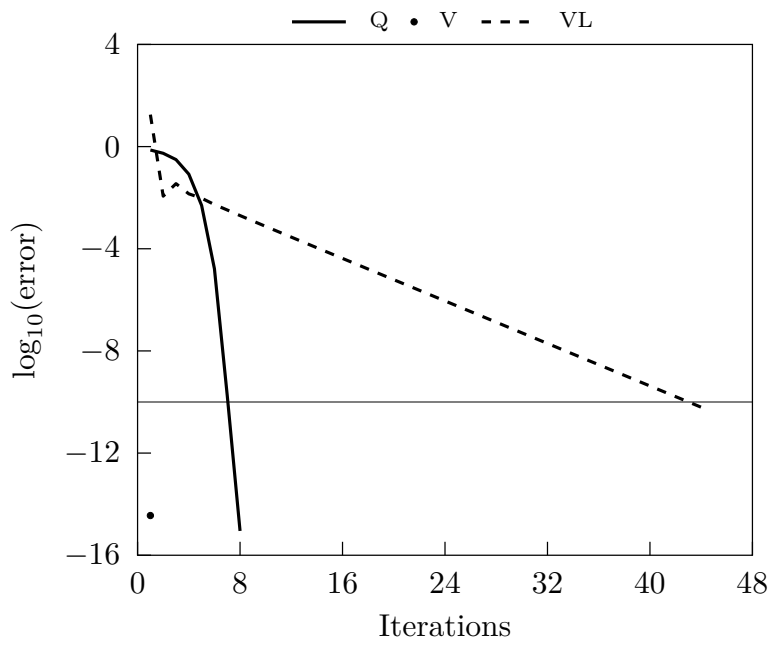

(a)

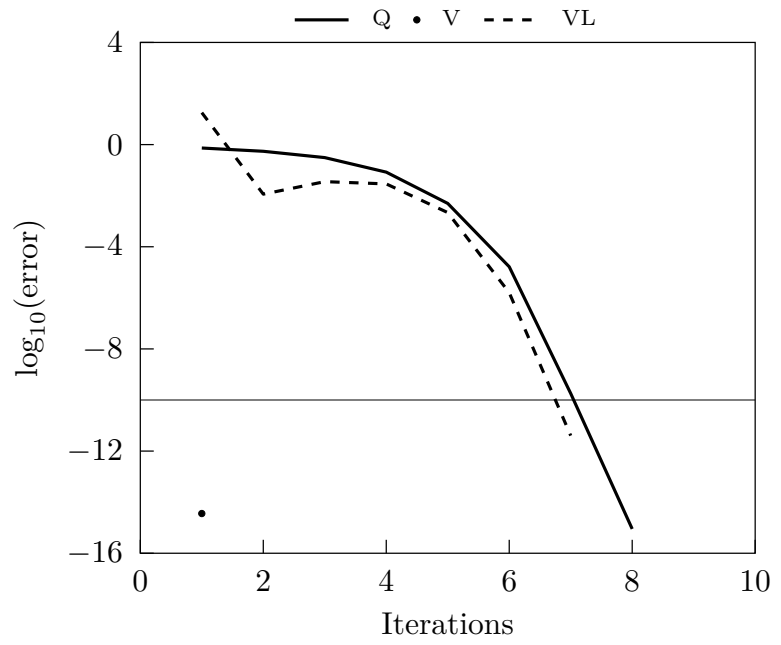

(b)

Figure 8: Convergence in acetic acid/ethanol esterification for an equimolar feed of reactants at $355 \mathrm{~K}$ and $1 \mathrm{~atm}$ with the successive substitution (a) and the combined algorithm (b).

\section{MTBE synthesis}

MTBE is synthesized from a mixture of isobutene and methanol: 


$$
\mathrm{C}_{4} \mathrm{H}_{8}+\mathrm{CH}_{4} \mathrm{O} \rightleftharpoons \mathrm{C}_{5} \mathrm{H}_{12} \mathrm{O}
$$

in the presence of $n$-butane as an inert. The vapor phase is considered ideal and the liquid phase is described by the Wilson activity coefficient model. ${ }^{25}$ The chemical equilibrium constant and parameters for the phase equilibrium model were reported in Ung and Doherty ${ }^{22}$. Formula matrix and stoichiometric matrix are:

$$
\mathbf{A}=\left[\begin{array}{llll}
1 & 0 & 0 & 1 \\
0 & 1 & 0 & 1 \\
0 & 0 & 1 & 0
\end{array}\right] \quad \mathbf{N}=\left[\begin{array}{llll}
-1 & -1 & 0 & 1
\end{array}\right]^{\mathrm{T}}
$$

In Figure 9, although the combined algorithm decreases the number of iterations for the single-phase convergence, the speed increase is clear for the two-phase case, which requires 4 times fewer iterations.

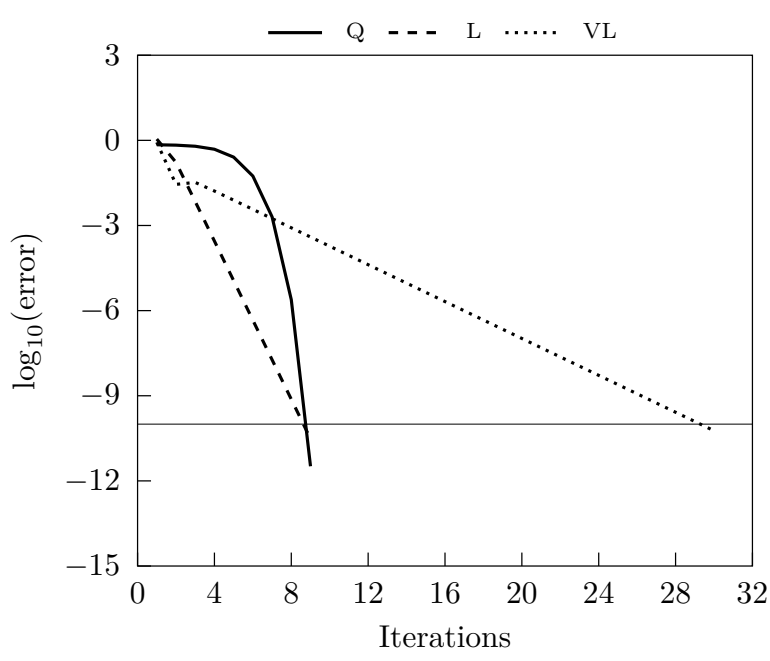

(a)

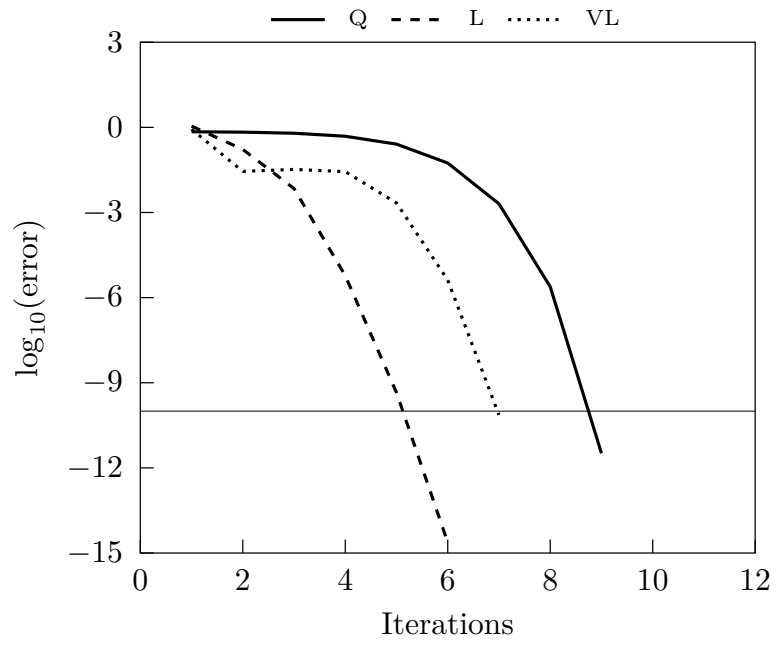

(b)

Figure 9: Convergence in MTBE synthesis for isobutene/methanol ratio 1:1.1 without inert at $320.92 \mathrm{~K}$ and $1 \mathrm{~atm}$ with the successive substitution (a) and the combined algorithm (b).

\section{Cyclohexane synthesis}

Cyclohexane can be synthesized by benzene hydrogenation: 


$$
\mathrm{C}_{6} \mathrm{H}_{6}+3 \mathrm{H}_{2} \rightleftharpoons \mathrm{C}_{6} \mathrm{H}_{12}
$$

Phase behavior is described by the PR equation of state ${ }^{30}$ without binary interaction parameters. Gibbs energy of formation is given in George et al. ${ }^{31}$. Formula matrix and stoichiometric matrix are:

$$
\mathbf{A}=\left[\begin{array}{lll}
1 & 0 & 1 \\
0 & 1 & 3
\end{array}\right] \quad \mathbf{N}=\left[\begin{array}{lll}
-1 & -3 & 1
\end{array}\right]^{\mathrm{T}}
$$

In Figure 10 the acceleration of calculations with the modified RAND in the final steps is evident. Especially for the two-phase case, calculations require three times fewer iterations.

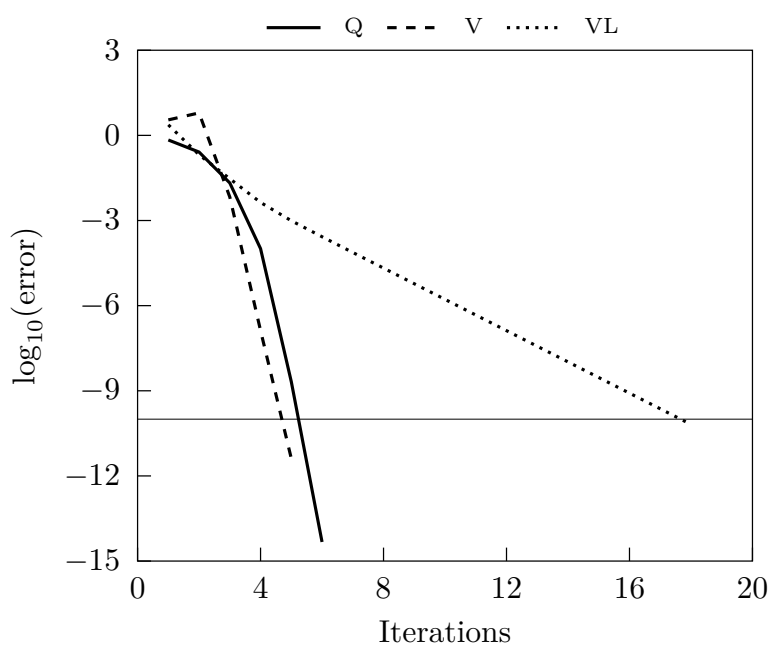

(a)

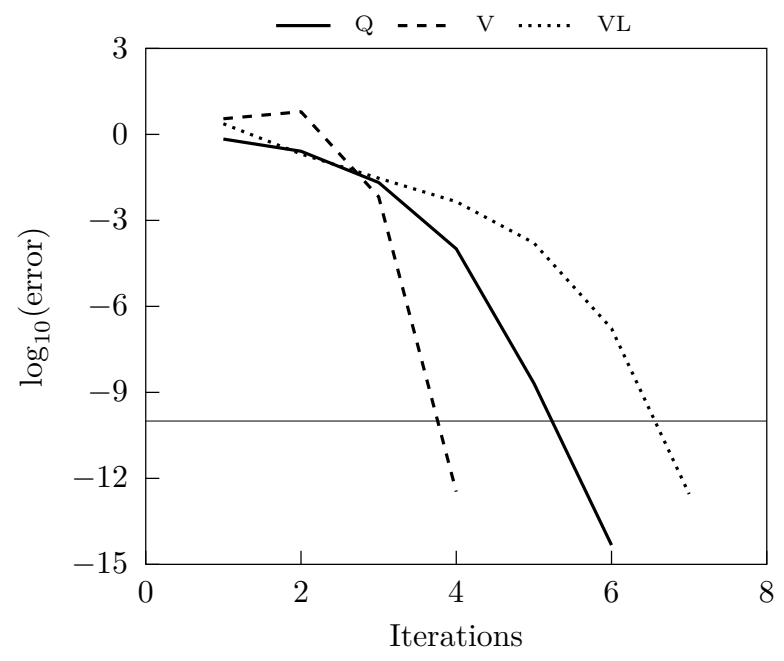

(b)

Figure 10: Convergence in cyclohexane synthesis for benzene/hydrogen ratio 1:3.05 at 500 $\mathrm{K}$ and $30 \mathrm{~atm}$ with the successive substitution (a) and the combined algorithm (b).

\section{Methanol synthesis}

Methanol synthesis is usually modeled by the following reactions: 


$$
\begin{gathered}
\mathrm{CO}+2 \mathrm{H}_{2} \rightleftharpoons \mathrm{CH}_{4} \mathrm{O} \\
\mathrm{CO}_{2}+\mathrm{H}_{2} \rightleftharpoons \mathrm{CO}+\mathrm{H}_{2} \mathrm{O}
\end{gathered}
$$

with methane and $n$-octadecane included in the system as inerts. Phase behavior is described by the SRK equation of state ${ }^{24}$ with binary interaction parameters reported by Castier et al. ${ }^{4}$. Reference state chemical potentials at 1 bar are given in Phoenix and Heidemann ${ }^{32}$. Formula matrix and stoichiometric matrix are:

$$
\mathbf{A}=\left[\begin{array}{lllllll}
1 & 1 & 0 & 0 & 1 & 0 & 0 \\
0 & 1 & 0 & 1 & 0 & 0 & 0 \\
0 & 0 & 1 & 1 & 2 & 0 & 0 \\
0 & 0 & 0 & 0 & 0 & 1 & 0 \\
0 & 0 & 0 & 0 & 0 & 0 & 1
\end{array}\right] \quad \mathbf{N}=\left[\begin{array}{ccccccc}
-1 & 0 & -2 & 0 & 1 & 0 & 0 \\
1 & -1 & -1 & 1 & 0 & 0 & 0
\end{array}\right]^{\mathrm{T}}
$$

Convergence of the three-phase methanol synthesis is shown in Figure 11. The first phase set, a single vapor phase, requires 54 outer loop iterations with successive substitution. When the modified RAND is employed after three successive substitution iterations, we need only four additional iterations for full convergence. For the subsequent phase sets, VL and VLL, the total number of iterations does not exceed eight, while using only successive substitution, the minimum number of outer loop iterations is 22 .

\section{Conclusions}

An efficient and robust algorithm combined of two non-stoichiometric methods is proposed for non-ideal multiphase equilibrium of multicomponent reaction systems. Calculations begin with the assumption of a single phase. A nested-loop procedure with successive substitution is used during the first steps and for final convergence calculations are performed by the 


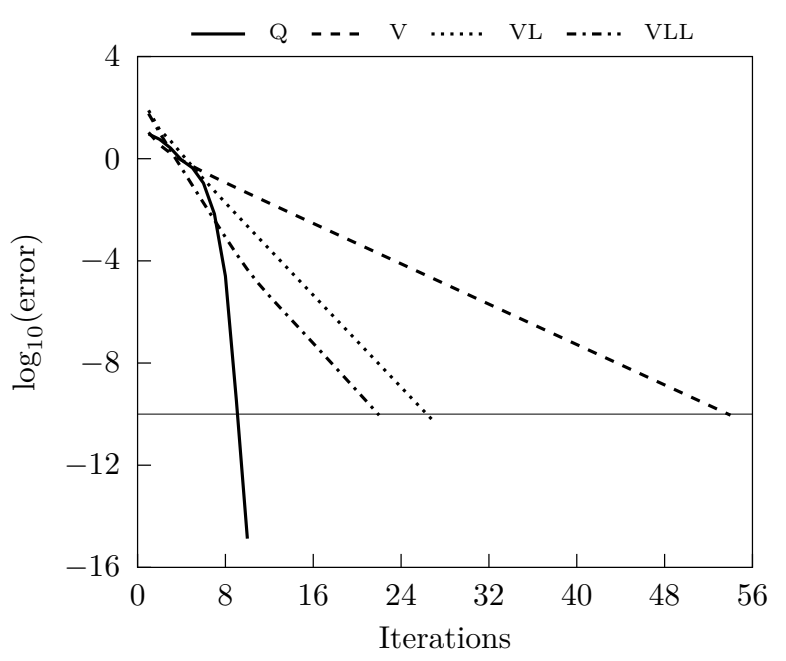

(a)

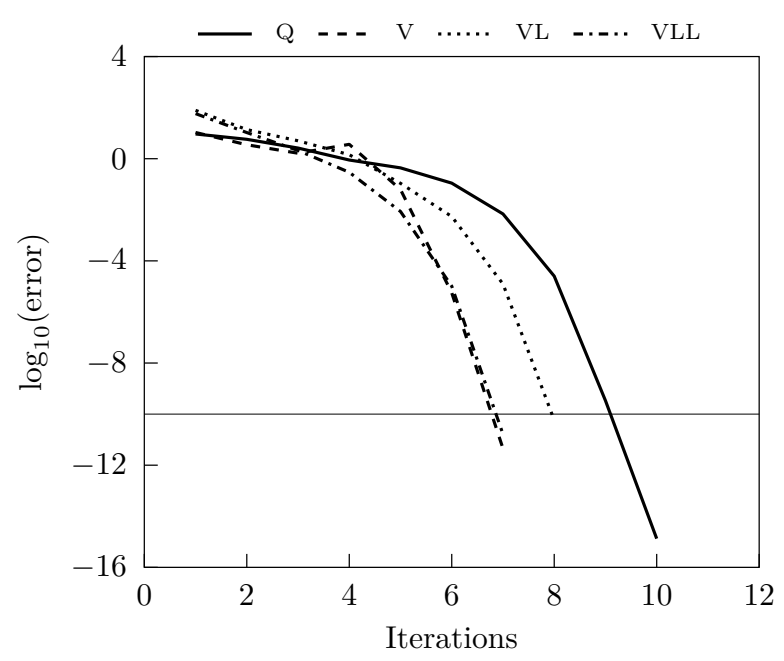

(b)

Figure 11: Convergence in methanol synthesis at $473.15 \mathrm{~K}$ and 101.3 bar with the successive substitution (a) and the combined algorithm (b).

modified RAND method. Successive substitution provides good quality initial estimates for modified RAND and stability analysis allows the sequential addition of the required number of phases at equilibrium. The convergence rate is linear in the beginning and quadratic in the final steps, due to the change of the procedure. No failure of convergence was observed for a number of systems examined, regardless of the thermodynamic model that described the phase behavior.

\section{Supporting information}

The current calculations in the cyclohexane synthesis were based on a temperature independent chemical equilibrium constant. We have also examined the effect of temperature dependence concerning chemical equilibrium. This information is available free of charge via the Internet at http://pubs.acs.org/.

\section{Acknowledgement}

The authors thank Prof. Michael L. Michelsen for his insightful comments and suggestions. 


\section{References}

(1) Smith, W. R.; Missen, R. W. Chemical Reaction Equilibrium Analysis: Theory and Algorithms; Wiley: New York, United States of America, 1982.

(2) Tsanas, C.; Stenby, E. H.; Yan, W. Calculation of Simultaneous Chemical and Phase Equilibrium by the Method of Lagrange Multipliers. Chemical Engineering Science 2017, $174,112-126$.

(3) Michelsen, M. L.; Mollerup, J. M. Thermodynamic Models: Fundamentals Ef Computational Aspects, 2nd ed.; Tie-Line Publications: Holte, Denmark, 2007.

(4) Castier, M.; Rasmussen, P.; Fredenslund, A. Calculation of simultaneous chemical and phase equilibria in nonideal systems. Chemical Engineering Science 1989, 44, 237-248.

(5) White, W. B.; Johnson, S. M.; Dantzig, G. B. Chemical Equilibrium in Complex Mixtures. The Journal of Chemical Physics 1958, 28, 751-755.

(6) Brinkley, S. R., Jr Calculation of the Equilibrium Composition of Systems of Many Constituents. The Journal of Chemical Physics 1947, 15, 107-110.

(7) Huff, V. N.; Gordon, S.; Morrell, V. E. General method and thermodynamic tables for computation of equilibrium composition and temperature of chemical reactions. National Advisory Committee for Aeronautics 1951, NACA Technical Report 1037, 829-885.

(8) Gautam, R.; Seider, W. D. Computation of phase and chemical equilibrium: Part I. Local and constrained minima in Gibbs free energy. AIChE Journal 1979, 25, 991-999.

(9) Gautam, R.; Seider, W. D. Computation of phase and chemical equilibrium: Part II. Phase-splitting. AIChE Journal 1979, 25, 999-1006.

(10) Gautam, R.; Seider, W. D. Computation of phase and chemical equilibrium: Part III. Electrolytic solutions. AIChE Journal 1979, 25, 1006-1015. 
(11) White, C. W., III; Seider, W. D. Computation of phase and chemical equilibrium: Part IV. Approach to chemical equilibrium. AIChE Journal 1981, 27, 466-471.

(12) Venkatraman, A.; Lake, L. W.; Johns, R. T. Gibbs Free Energy Minimization for Prediction of Solubility of Acid Gases in Water. Industrial \& Egineering Chemistry Research 2014, 53, 6157-6168.

(13) Venkatraman, A.; Lake, L. W.; Johns, R. T. Modelling the impact of geochemical reactions on hydrocarbon phase behavior during $\mathrm{CO}_{2}$ gas injection for enhanced oil recovery. Fluid Phase Equilibria 2015, 402, 56-68.

(14) Voňka, P.; Leitner, J. Calculation of chemical equilibria in heterogeneous multicomponent systems. Calphad 1995, 19, 25-36.

(15) Greiner, H. An efficient implementation of Newton's method for complex nonideal chemical equilibria. Computers \& Chemical Engineering 1991, 15, 115-123.

(16) Paterson, D.; Michelsen, M. L.; Stenby, E. H.; Yan, W. New Formulations for Isothermal Multiphase Flash. 2017; Submitted under the title "RAND-Based Formulations for Isothermal Multiphase Flash" to Society of Petroleum Engineers Journal (accepted).

(17) Michelsen, M. L. The isothermal flash problem. Part I. Stability. Fluid Phase Equilibria 1982, 9, 1-19.

(18) Wasylkiewicz, S. K.; Ung, S. Global phase stability analysis for heterogeneous reactive mixtures and calculation of reactive liquid-liquid and vapor-liquid-liquid equilibria. Fluid Phase Equilibria 2000, 175, 253-272.

(19) Abrams, D. S.; Prausnitz, J. M. Statistical Thermodynamics of Liquid Mixtures: A New Expression for the Excess Gibbs Energy of Partly or Completely Miscible Systems. AIChE Journal 1975, 21, 116-128. 
(20) Okasinski, M. J.; Doherty, M. F. Prediction of heterogeneous reactive azeotropes in esterification systems. Chemical Engineering Science 2000, 55, 5263-5271.

(21) Bonilla-Petriciolet, A.; Bravo-Sánchez, U. I.; Castillo-Borja, F.; Frausto-Hernández, S.; Segovia-Hernández, J. G. Gibbs Energy Minimization Using Simulated Annealing for Two-phase Equilibrium Calculations in Reactive Systems. Chemical and Biochemical Engineering Quarterly 2008, 22, 285-298.

(22) Ung, S.; Doherty, M. F. Vapor-liquid phase equilibrium in systems with multiple chemical reactions. Chemical Engineering Science 1995, 50, 23-48.

(23) Stateva, R. P.; Wakeham, W. A. Phase Equilibrium Calculations for Chemically Reacting Systems. Industrial \& Engineering Chemistry Research 1997, 36, 5474-5482.

(24) Soave, G. Equilibrium constants from a modified Redlich-Kwong equation of state. Chemical Engineering Science 1972, 27, 1197-1203.

(25) Wilson, G. M. Vapor-Liquid Equilibrium. XI. A New Expression for the Excess Free Energy of Mixing. Journal of the American Chemical Society 1964, 86, 127-130.

(26) Chen, F.; Huss, R. S.; Doherty, M. F.; Malone, M. F. Multiple steady states in reactive distillation: kinetic effects. Computers \& Chemical Engineering 2002, 26, 81-93.

(27) Maurer, G. Vapor-Liquid Equilibrium of Formaldehyde-and Water-Containing Multicomponent Mixtures. AIChE Journal 1986, 32, 932-948.

(28) Saito, S.; Michishita, T.; Maeda, S. Separation of meta- and para-xylene mixture by distillation accompanied by chemical reactions. Journal of Chemical Engineering of Japan 1971, 4, 37-43.

(29) Xiao, W.-d.; Zhu, K.-h.; Yuan, W.-k.; Chien, H. H.-y. An algorithm for simultaneous chemical and phase equilibrium calculation. AIChE Journal 1989, 35, 1813-1820. 
(30) Peng, D.-Y.; Robinson, D. B. A New Two-Constant Equation of State. Industrial \& Engineering Chemistry Fundamentals 1976, 15, 59-64.

(31) George, B.; Brown, L. P.; Farmer, C. H.; Buthod, P.; Manning, F. S. Computation of Multicomponent, Multiphase Equilibrium. Industrial \&3 Engineering Chemistry Process Design and Development 1976, 15, 372-377.

(32) Phoenix, A. V.; Heidemann, R. A. A non-ideal multiphase chemical equilibrium algorithm. Fluid Phase Equilibria 1998, 150-151, 255-265.

\section{Table of Contents (TOC) Graphic}

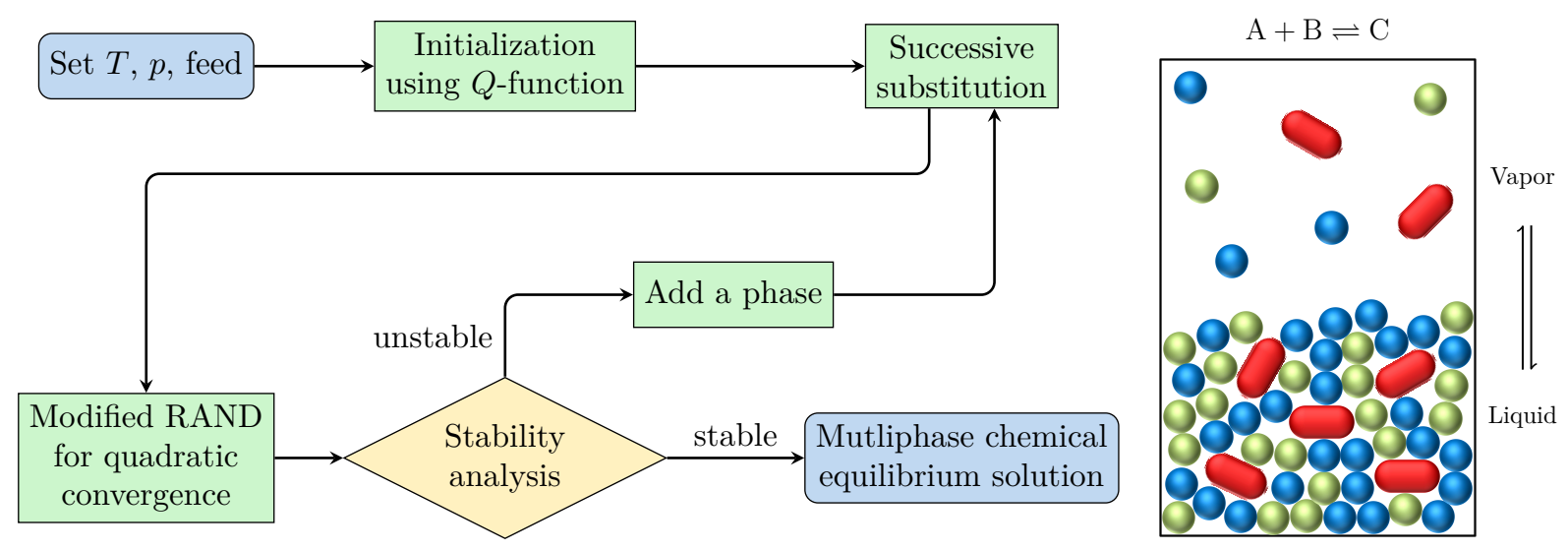

